$$
\begin{aligned}
& \text { Report No. BMI-1397 } \\
& \text { UC-81 Reactors - Power } \\
& \text { (TID-4500, 15th Ed.) }
\end{aligned}
$$

Contract No. W-7405-eng-92

\title{
MODEL STUDIES OF FLOW AND MIXING \\ IN THE PARTIALLY ENRICHED \\ GAS-COOLED POWER REACTOR
}

\author{
by \\ Lawrence J. Flanigan \\ Gale R. Whitacre \\ Herbert R. Hazard
}

November 30,1959

\section{BATTELLE MEMORIAI INSTITUTE $505 \mathrm{King}$ Avenue \\ Columbus 1 , Ohio}




\section{DISCLAIMER}

This report was prepared as an account of work sponsored by an agency of the United States Government. Neither the United States Government nor any agency Thereof, nor any of their employees, makes any warranty, express or implied, or assumes any legal liability or responsibility for the accuracy, completeness, or usefulness of any information, apparatus, product, or process disclosed, or represents that its use would not infringe privately owned rights. Reference herein to any specific commercial product, process, or service by trade name, trademark, manufacturer, or otherwise does not necessarily constitute or imply its endorsement, recommendation, or favoring by the United States Government or any agency thereof. The views and opinions of authors expressed herein do not necessarily state or reflect those of the United States Government or any agency thereof. 


\section{DISCLAIMER}

Portions of this document may be illegible in electronic image products. Images are produced from the best available original document. 


\section{TABLE OF CONTENTS}

Page

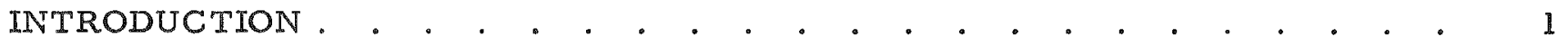

DESCRIPTION OF THE MODEL . . . . . . . . . . . . . . . . . . 1

Mechanical Design . . . . . . . . . . . . . . . . . . . 1

Hydrodynamic Design . . . . . . . . . . . . . . . . 6

Model Setup and Operation . . . . . . . . . . . . . . . 6

SEQUENCE OF MODEL ALTERATIONS AND TESTS • . . • . . . . $\quad$. 7

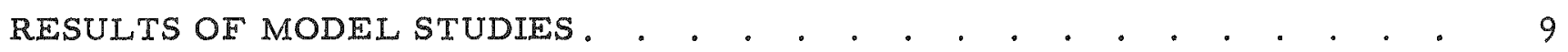

Core-Flow Distribution . . . . . . . . . . . . . . . . . . . . 9

Mixing Studies . . . . . . . . . . . . . . . . . . . . 10

Studies of Thermal-Shield-Coolant Flow . . . . . . . . . . . . 14

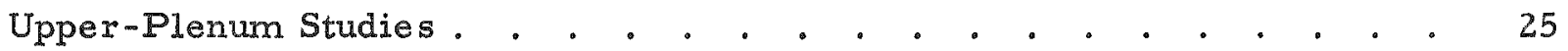

Lower-Plenum Studies . . . . . . . . . . . . . . . . 25

Transition Studies . . . . . . . . . . . . . . . . . . . . 30

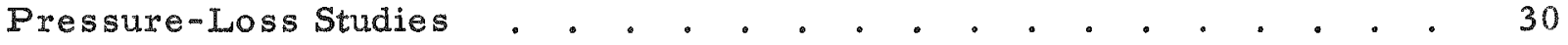

PROTOTYPE PRESSURE LOSSES . . • . • . . . . . . . . . . . . 33

ACKNOWLEDGMENTS • . . . . . . . . . . . . . . . . . . . 34 


\title{
MODEL STUDIES OF FLOW AND MIXING IN THE PARTIALLY ENRICHED GAS-COOLED POWER REACTOR.
}

\author{
Lawrence J. Flanigan, Gale R. Whitacre, and Herbert R. Hazard
}

\begin{abstract}
1 quarter-scale flow model, using air as a working fluid, us used to obtuin design data for the PEGCPR program. 1 design for the core-support cylinder, to provide optimum mixing and core-flou distribution, was developed. following which experimental studies of core-flow distribution, mixing of flow from the two inlets, flow patterns in plenum spaces, flow patterns in the thermal-shield-coolant passage, and pressure drops throughout the model were carried out. Results obtained in the model were then converted to values applicable to helium flow in the prototype.
\end{abstract}

\section{INTRODUCTION}

In a program of assistance to Kaiser Engineers on the Partially Enriched GasCooled Power Reactor (PEGCPR), Battelle conducted studies of reactor coolant flow and mixing in a quarter-scale model. The Kaiser PEGCPR program had as its objective the design of a 40-mw electrical output, helium-cooled, partially enriched uranium-fueled, graphite-moderated power reactor. The design and assembly of the model and the flow studies were carried out at Battelle. Plastic parts for the model pressure vessel and thermal shield were fabricated by the Magic Circle Tool and Engineering Company, Independence, Missouri, and the model core was constructed at Battelle. All results from the model program, to date, are included in this report.

While model studies were in progress the end use of the reactor was changed from power generation to experimental use. This resulted in design changes which were not included in the flow model, but which would be expected to have only minor effects on. the flow data reported here. The reoriented program is designated as the Experimental Gas-Cooled Reactor program.

\section{DESCRIPTION OF THE MODEL}

\section{Mechanical Design}

The quarter-scale flow model was designed to simulate flow conditions throughout the PEGCPR with the exception of those within the fuel channels. Ir tsese, friction pressure losseswere simulated with orificed tubes having appropriate flow resistances. The model was constructed of glass-fiber-reinforced epoxy resin throughout with the exception of the core, which was constructed of aluminum plates and tubes.

Figure 1 is a photograph showing the quarter-scale model setup for air-flow studies. Four centrifugal blowers connected in series supplied air to the model through the upper duct above the panel board. Air leaving the model was discharged through the roof of the building. The large manometer panel shown at the right in the photograph 


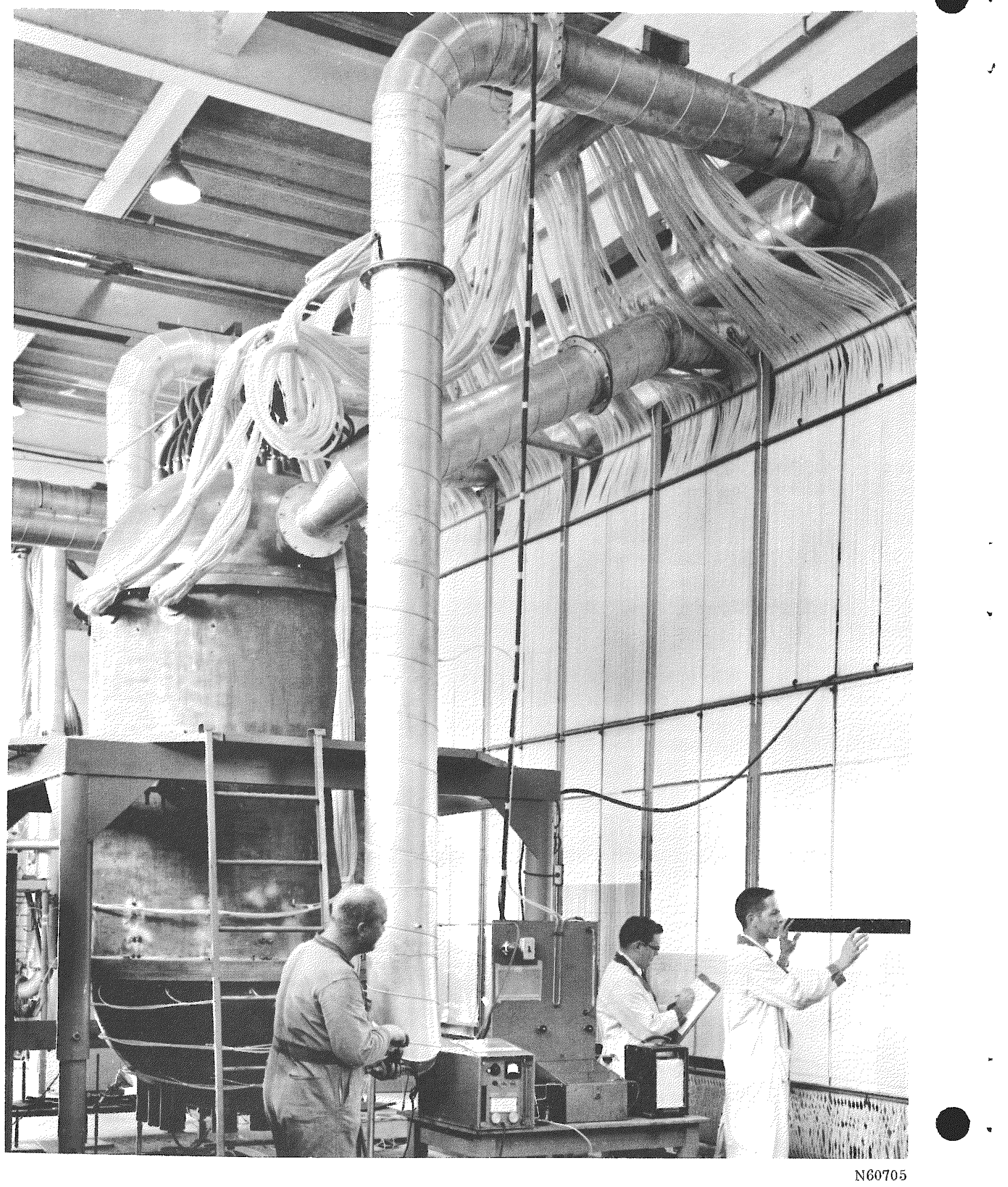

FIGURE 1. QUARTER-SCALE MODEL OF THE PEGCPR SETUP FOR AIR-FLOW STUDIES 
was used to measure pressures throughout the model. The inlet piping was designed to provide a flat velocity profile at the entrance to the model. Provisions were made for equalizing flow in the inlets and outlets. For operation with one loop, the inactive inlet and outlet were blocked with plates installed between piping flanges.

Figure 2 is a vertical cross section of the model showing the general arringement of the pressure vessel, the inlets and outlets, the themal shield, the upper and lower plenums, the core, and the internal instrumentation.

Figure 3 is a horizontal cross section of the model showing the arrangement of the thermal shield, the core fucl assemblies, and the shield-passage instrumenation.

Air, simulating reactor coolant, entered through one or both inlets at the bottom of the model and through 61 nozzles in the top dome. The air which entered through the 29 control-rod nozzles and the 32 flux-scanning nozzles passed downward through the annular space between the thermal shield and the pressure vessel to the inlet plenum where it joined the flow from the inlet nuzzles. About 3 per cent of the total model flow passed through the thermal-shield-coolant passage. From the inlet plenum the coolant passed through 30 holes in the core-suppoxt cylinder into the lower plenum below the core and then upwat through 248 uniformly orificed simulated fuel channels. Flow from the cure discharged into the upper plenum and passed out of the model through one or both outlet nozzles.

The model core, as shown in Figure 2, consisted of two parts separated at the tube sheets just above the bottom flange of the model. The upper assembly contained 248 straight aluminum tubes $3 / 4-\mathrm{in}$. in ID and $61 \mathrm{in}$. in length each simulating a fuel channel. Each tube was grooved at the ends for O-rings which sealed it into two tube sheets. The tube sheets were attached at their circumlerence to the plastic core cylinder. The lowe $\mathrm{r}$ assembly consisted of a single tube sheet into which 248 extension tubes, each about $16 \mathrm{in.}$ long, were screwed and comented with epoxy resin. The ends of each group of 16 tubes were disposed over a partial spherical surface with its centex in the fuelloading port directly below the center line of the group. Ihe pressure loss of the core was established by the diameters of 248 identical sharp-edged oxifices, one in each tube. These orifices are also used for flow measurement to determine flow distribution within the core.

Each orifice was a circular disk bored with a sharp-edged hole 0.458 in. in diameter and fitted with an $\mathrm{O}$-ring in a groove in the downstream side. These orifice plate: were attached to the bottom tube sheet of the upper part of the core by two screws. tightened for metal-to metal contact. 'The upstream side of the orifice plate was sealed by encircling it with an $\mathrm{O}-\mathrm{ring}$ slightly thicker than the plate. When the extension-tube plate was installed, the se O-rings were compressed between the two tube plutes so that the orifice was completely sealed against leakage. With this arrangement it was relatively easy to replace orifices to change flow resistances in various parts of the core. However, such changes were not made during this investigation. Upstream pressure taps were located in the extension tubes just upstream from the orifice. Downstream pressure taps were located at the downstream ends of the core tubes, so that the pressures measured for each orifice were, essentially, the upper-plenum and lower-plenum pressures at the tube location under flow conditions. The instrument tubing from the orifice pressure taps was carried out of the model through burst-slug detector nozzles above the core, which avoided intexference with flow in the thermal-shield coolant channel. 


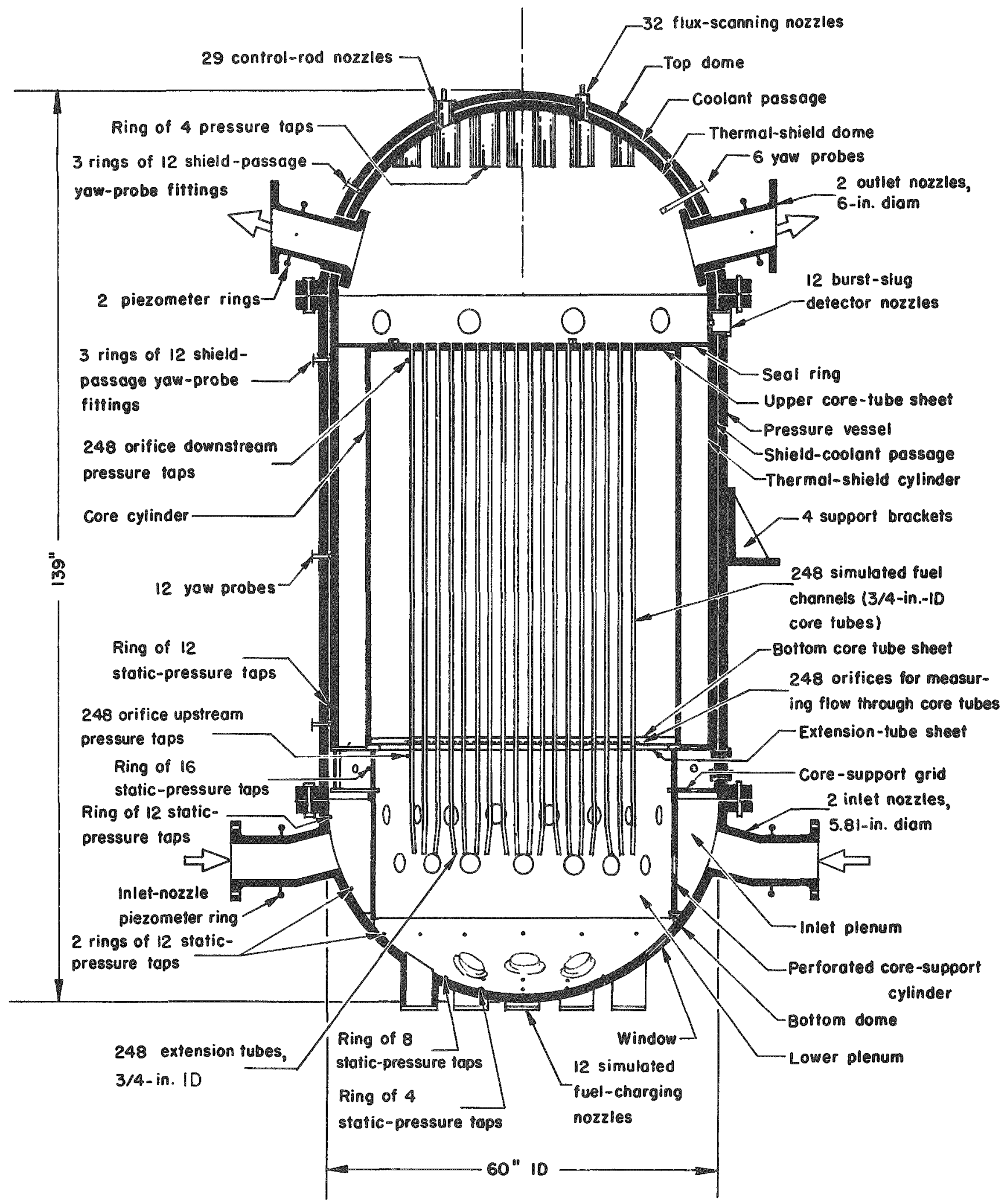

FIGURE 2. VERTICAL SECTION OF QUARTER-SCALE FLOW MODEL OF THE PEGCPR 


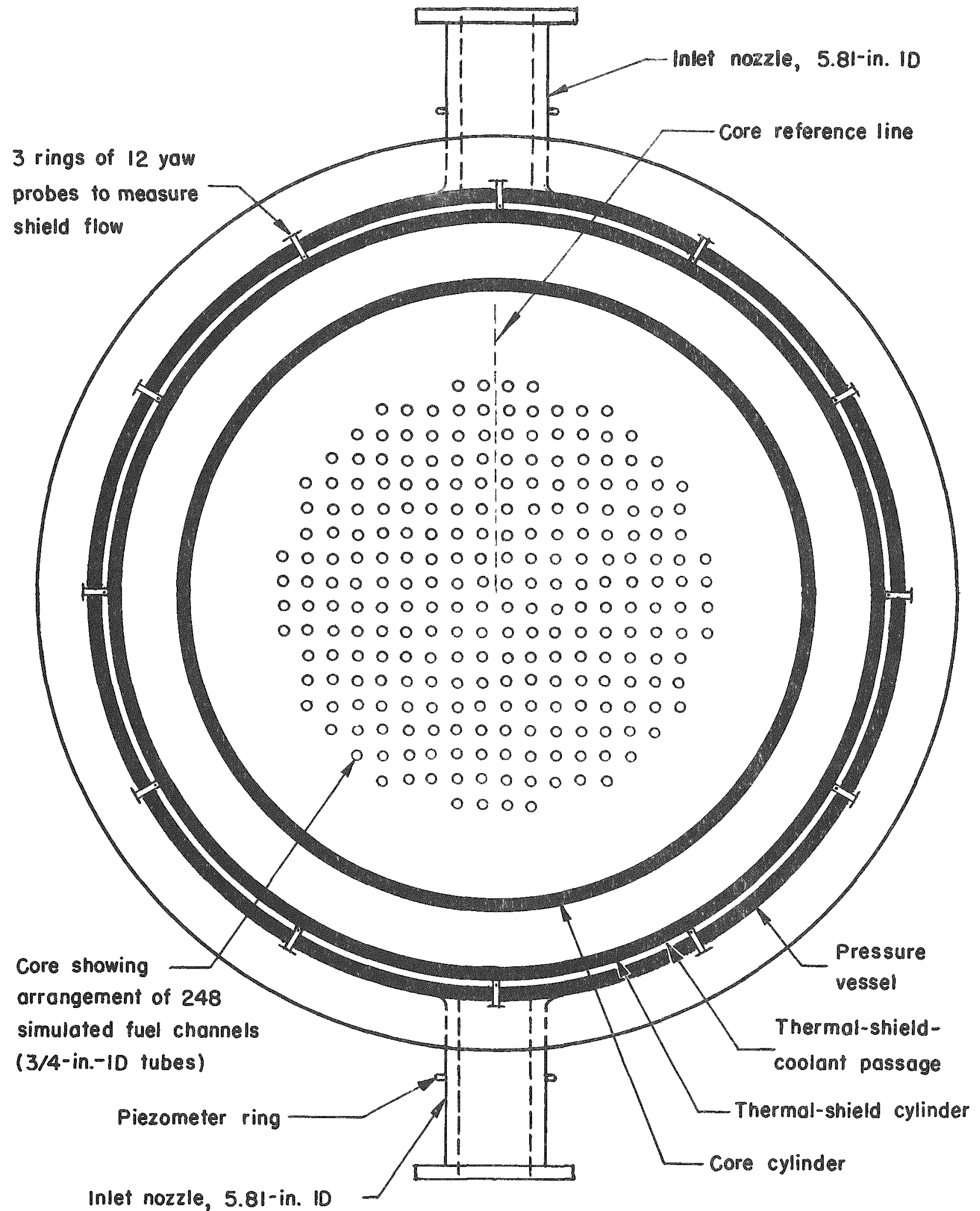

$\times 6249-4$

FIGURE 3. HORIZ ONTAL SECTION THROUGH CORE OF OUARTER-SCALE FLOW MODEL OF THE PEGCPR 


\section{Hydrodynamic Design}

In making model studies of flow, it is desirable to have dynamic similarity of model and prototype to insure that data from the model will accurately predict prototype performance. By definition, dynamic similarity is achieved when the Reynolds number for flow in the prototype is equal to the Reynolds number for flow in a geometrically similar model.

For the PEGCPR prototype using helium as the coolant, the Reynolds number in the inlet nozzles, which is representative of Reynolds numbers in the upper-and lowerplenum regions, is about 1,920,000. For the quarter-scale flow model the inlet-nozzle Reynolds number was about 710,000 which is approximately 40 per cent of the prototype value. At this value of Reynolds number, which is well into the turbulent range, dynamic similaxity is assured. However, in the thermal-shield-coolant passage, prototype helium velocities are low, and Reynolds numbers in the range of 5000 to 7000 occur. Since these are close to the transition range, where flow effects may vary considerably with Reynolds number, it appeared desirable to study flow in this region both with the proper proportion of flow through the region, giving Reynolds numbers in the xange of 2000 to 2800 , and with greater flow to raise Reynolds numbers to match those in the prototype.

The internal design of the model core was not geometrically similar to that of the prototype, but was simulated with round tubes containing orifices designed to provide core-flow distribution and pressure drop equal to those which would be obtained with dynamic similarity. Thus, although dynamic similarity was not achieved within the core structure, the effects on other components of the model were the same as those which would occur with dynamic similarity.

\section{Model Setup and Operation}

The model was set up so that flow conditions could be closely controlled. Details of piping and external instrumentation may be seen in Figure 1.

The inlet piping was designed to simulate the prototype piping. A flow-measuring nozzle in each inlet and an orifice in each outlet pipe measured inlet and outlet flow rates. A damper in each inlet and outlet pipe controlled flow. Flow through inlets and outlets was equalized for most tests. The approach piping, carrying air at pressures to $4 \mathrm{psi}$ and temperatures to $180 \mathrm{~F}$, was constructed with turning vanes in the elbows to minimize flow disturbances approaching the inlet nozzles.

Pressure taps for the 248 flow-measuring orifices in the core and for 116 static pressures throughout the model were connected to a specially constructed manometer board having 680 tubes each suitable for measurement of pressures of up to 160 in. of water. The manometer board consisted of six well-type manometers, each having one leveling tank and a number of manometer tubes. The tubes were connected to henders at the bottom of the board and the pressures to be measured were applied at their tops. The manometer tubes were made of translucent polyethylene plastic. In use, pressure depressed the level of the water in individual manometer tubes, and the taxk levels were adjusted to suitable heights for easy reading. Each tank level showed on one. 
manometer tube, and the measured pressures were the differences in height between this level and the reading of each tube in the manometer. Orifice differentials and reading accuracy were such that flow measurements were reproduced to \pm 0.2 per cent in successive tests.

Inlet-plenum pressures were obtained with two rings of 12 static-pressure taps, as shown in Figure 2. Lower-plenum pressures were measured with 24 static-pressure taps arranged in rings of 12,8 , and 4 taps. Upper-plenum pressures were obtained with one ring of 12 static-pressure taps.

Flow directions and velocities in the thermal-shield-coolant passage were measured with cylindrical three-hole yaw probes using inclined manometers sensitive to $0.002 \mathrm{in}$. of water. In stagnation areas a hot-wire anemometer sensitive to a velocity of about 0.2 fps was used.

Mixing studies were conducted by injecting measured concentrations of $\mathrm{SO}_{2}$ into one inlet and determining the concentration of $\mathrm{SO}_{2}$ in the air passing through each of the 248 simulated fuel assemblies in the core.

Flow patterns in the upper plenum were determined by injecting $\mathrm{TiCl}_{4}$ smoke into the plenum and visually observing the flow patterns. Flow velocities and directions near the wall were measured using a three-hole cylindrical yaw probe.

\section{SEQUENCE OF MODEL ALTERATIONS AND TESTS}

Operation of the quarter-scale flow model was begun on June 30, 1959, with a calibration of the individual flow-measuring orifices in the simulated fuel assemblies. In calibration, air metered by a master orifice was piped into each simulated assembly in the model. The flow rate was varied from assembly to assembly to provide the same static pressure at the entrance to each assembly. The reading of the measuring orifice in each assembly was obtained from the manometer panel. This calibration provided the orifice pressuxe differentials which would be obtained with a uniform pressure field at the entrance and exit of the simulated fuel assemblies. Any deviations obtained during model operation reflect nonuniform pressure fields.

Following calibration, Tests $5,6,7$, and 8 were run to obtain core-flow distribution, mixing, and smoke-study data with a sheet-metal core-support cylinder positioned so that one of the sixteen 3 -in.-diameter holes in the bottom ring was rotated. 0.7 deg clockwise from the center line of one inlet. The core-support cylinder is shown in Figure 2 .

The core-support cylinder was then rotated so that one of the 16 holes in the upper ring was in line with the inlet. Tests 9, 10, 11, and 12 were run to obtain core-flow distribution, mixing, and smoke-study data.

On Test 13 the core-support cylinder was positioned so that one hole in the bottom ring was aligned with the inlet center line. The top ring of holes was blocked. Coreflow-distribution and pressure-drop data were obtained. 
In Test 14, the position of the core-support cylinder remained the same as for Test 13 and the upper ring of holes was unblocked. Core-flow-distribution and pressuredrop data were taken.

Tests 16,17 , and 18 were run with the core-support cylinder positioned so that the center line of the inlet was midway between the center lines of the holes in the upper and lower rings. Mixing data and core-flow-distribution data were obtained.

Test 19 was a duplicate of Test 17 run to check reproducibility of flow measurements. Data for 95 per cent of the simulated fuel channels were reproduced within \pm 0.2 per cent, with remaining data within 0.3 per cent.

In Tests 20,21, and 22 core-flow-distribution data and lower-plenum mixing data were obtained with the core-support cylinder rotated 2.8 deg clockwise, viewed from above, and with the two holes in the upper ring, one nearest each of the two inlets, blocked.

Following Test 22 an evaluation of data for all core-support-cylinder configurations showed that all configurations provided good flow conditions, although some were better than others. The configurations in which the two holes in the upper ring nearest the inlets were blocked resulted in considerable reduction in impingement of highvelocity jets on the bottom of the core. As a best compromise between core-flow distribution, mixing pressure drop, and impingement of flow on the bottom of the core, the configuration studied in Tests 16,17, and 18 was selected. A plastic core-support cylinder with the 1-in. prototype thickness and with this optimum hole pattern was then made and used for all subsequent studies. This cylinder was $46-3 / 4$ in. in OD, $19-7 / 16$ in. high, and $1 / 4$ in. thick. A ring of 16 equally spaced holes of 3 -in. diameter was located with centers $7-3 / 4$ in. above the bottom of the cylinder, and a second ring of holes was located with centers 15-1/2 in. above the bottom. The holes in the upper ring were staggered so that they were located halfway between those in the lower ring, and two of them, one nearly in line with each inlet, were omitted to avoid jet impingement on the bottom of the core. The cylinder was oriented so that a hole in the bottom ring was displaced $1 / 128$ of the circumference, or $2.81 \mathrm{deg}$, from the center line of the inlet, in a clockwise direction as viewed from above, as their orientation improved performance over that for Tests 16,17 , and 18 .

Following installation of the plastic core-support cylinder in the mode1, Tests 23 and 24 were run to obtain core-flow-distribution data for operation with one and two loops.

Test 25 was run to determine the amount of mixing occurring in the lower plenum.

In Test 26 the thermal-shield-coolant flow rate was varied from 0 to 5 per cent of model flow to determine the effect of shield-coolant flow on core-flow distribution. No measurable effect was found.

In Test 27 a study was made of transition from two-loop to one-loop operation to check the effect on core-flow distribution and flow stability.

Tests 28 and 29 were run at reduced flow rates to measure the changes in coreflow distribution and pressure los ses resulting from reduced model Reynolds numbers. No effects were found. 
Uppex-plenum flow studies using $\mathrm{TiCl}_{4}$ smoke to obtain flow patterns and usirg a yaw probe to measure velocities near the surface of the dome were run with both one and two loops operating in Tests $30,31,32$, and 33.

Flow velocities and directions in the thermal-shield-coolant passage were measured in Test 34 using a coolant-flow rate such that the shield Reynolds number equaled that in the prototype with a coolant flow of 3-1/2 per cent of reactor flow with two loops operating.

In Test 35 shield coolant velocities and directions were measured at a Reynolds number equal to that obtained in the prototype with $2-1 / 2$ per cent shield flow for twoloop operation.

Test 36 was run with the same coolant-flow rate as Test 34 except that only one loop was operating. Since the prototype one-loop flow rate is assumed to be one-half of the two-loop flow rate, the shield Reynolds number equaled that in the prototype with a. coolant flow of 7 per cent of reactor flow.

Test 37 was run to obtain shield-coolant velocities and directions for operation with one loop at a shield-coolant-flow rate of $3-1 / 2$ per cent of model flow.

In Test 38 flow velocities were measured near the surface of the bottom dome in the inlet and lower plenums for operation with one loop.

In Tests 39 and 40 thermal-shield-coolant velocities and directions were meisured with two loops operating using shield-coolant-flow rates of $3-1 / 2$ per cent and $2-1 / 2$ per. cent of model flow, respectively.

Test 41 was run to measure flow velocities and directions in the lower plenum noar the junction of the bottom dome and the core-support cylinder with two loops operating.

Test 42 and 43 were rum to measure flow velocities and directions in the thermalshield-coolant passage using a hot-wire anemometer probe in areas where no measure ments could be obtained with a conventional three-hole yaw probe.

Test 44 was run to obtain shield-coolant velocities and directions for one-loop operation at a shield-coolant-flow rate of 2-1/2 per cent of model flow.

\section{RESULTS OF MODEL STUDIES}

\section{Core-Flow Distribution}

The core of the model contained 248 simulated fuel channels as previously described.

Each simulated fuel assembly in the model included an orifice which provided the core pressure drop and served as a flowmeter. Upstream and downstream orifice pressure taps were connected to a 680-tube water manometer, shown in Figure 1. In 
each test, orifice pressures were used to compute flow-distribution data by calculating the flow through each orifice using coefficients obtained from an in-place calibration, dividing each flow by the average for the core, and expressing the results as percentage of average flow for the core. These calculations were made using a digital computer.

Figure 4 is a plan view of the core showing the identification numbers of the simulated fuel channels. Shading of annular areas is used to aid in tracing numbers, and has no physical significance.

Figure 5 is a map of the core in which channel locations are marked with the value of flow through each channel for two-loop operation. The greatest deviations from average flow were +1.0 per cent in channels 164 and 208 , and -0.8 per cent in channel 125 .

Figure 6 is a map of the core showing core-flow distribution for one-loop operation. In this test, flow for each channel was within +1.3 and -1.4 per cent of the average flow for the core.

Core-flow-distribution studies were made at two reduced model flow rates. The lowest flow rate was 70 per cent of full model flow. Within the limits of data accuracy, flow distribution in the core was not affected by the reduction in Reynolds number of about 30 per cent.

In the model, core pressure loss was 75 per cent of over-all model pressure loss. In the prototype, the core loss is about 95 per cent of the over-all loss. Therefore, core-flow distribution for the model should be affected more by pressure gradients in plenum spaces than that for the prototype. That is, the model data are somewhat conservative.

\section{Mixing Studies}

Mixing studies were conducted by injecting measured concentrations of $\mathrm{SO}_{2}$ into the Loop 1 inlet, and determining the concentration of $\mathrm{SO}_{2}$ in the air passing through each of the 248 simulated fuel as semblies in the core. The $\mathrm{SO}_{2}$ was supplied from a pressurized gas cylinder. Because of the extremely low volume of $\mathrm{SO}_{2}$ required, it was mixed with a much larger volume of compressed air, and the mixture was injected into the inlet piping. The injector consisted of five 1/8-in. aluminum tubes having 21 holes, $0.021-$ in. in diametex, located at the centers of equal areas. It was located $19 \mathrm{ft}$ upstream of the model inlet in a horizontal run of pipe. With this arrangement, mixing ahead of the model was such that the deviations from the average concentration of about $10 \mathrm{ppm}$ of $\mathrm{SO}_{2}$ measured at the model inlet were always less than 5 per cent. The accuracy of mixing data from the model core would be similar, as all factors influencing accuracy are present in data taken at both locations.

Samples of air from each of the 248 simulated fuel assemblies were bled continuously from the upstream pressure taps of the flow-measuring orifices through the manometer tubes previously used for pressure measurement. These were detached from the manometer headers and allowed to vent air continuously. A sample for analysis was drawn from each manometer tube in turn, and analyzed immediately in a Titrilog, which recorded the concentration of $\mathrm{SO}_{2}$. With this procedure, it was possible to 


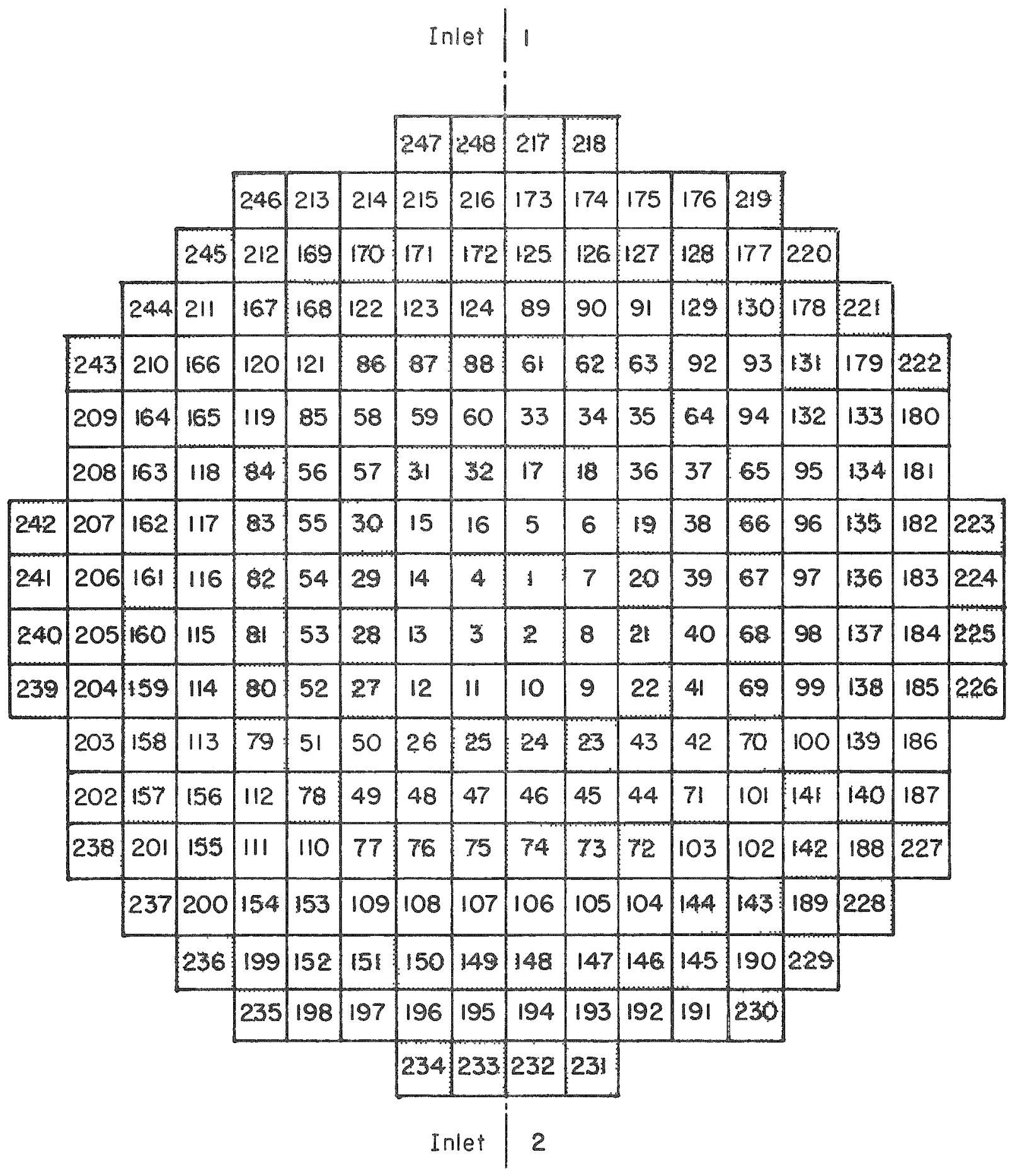

FIGURE 4. CROSS SECTION UF MODEL CORE SHOWING NUMBERING OF SIMULATED FUEL A.SSEMBLIES 


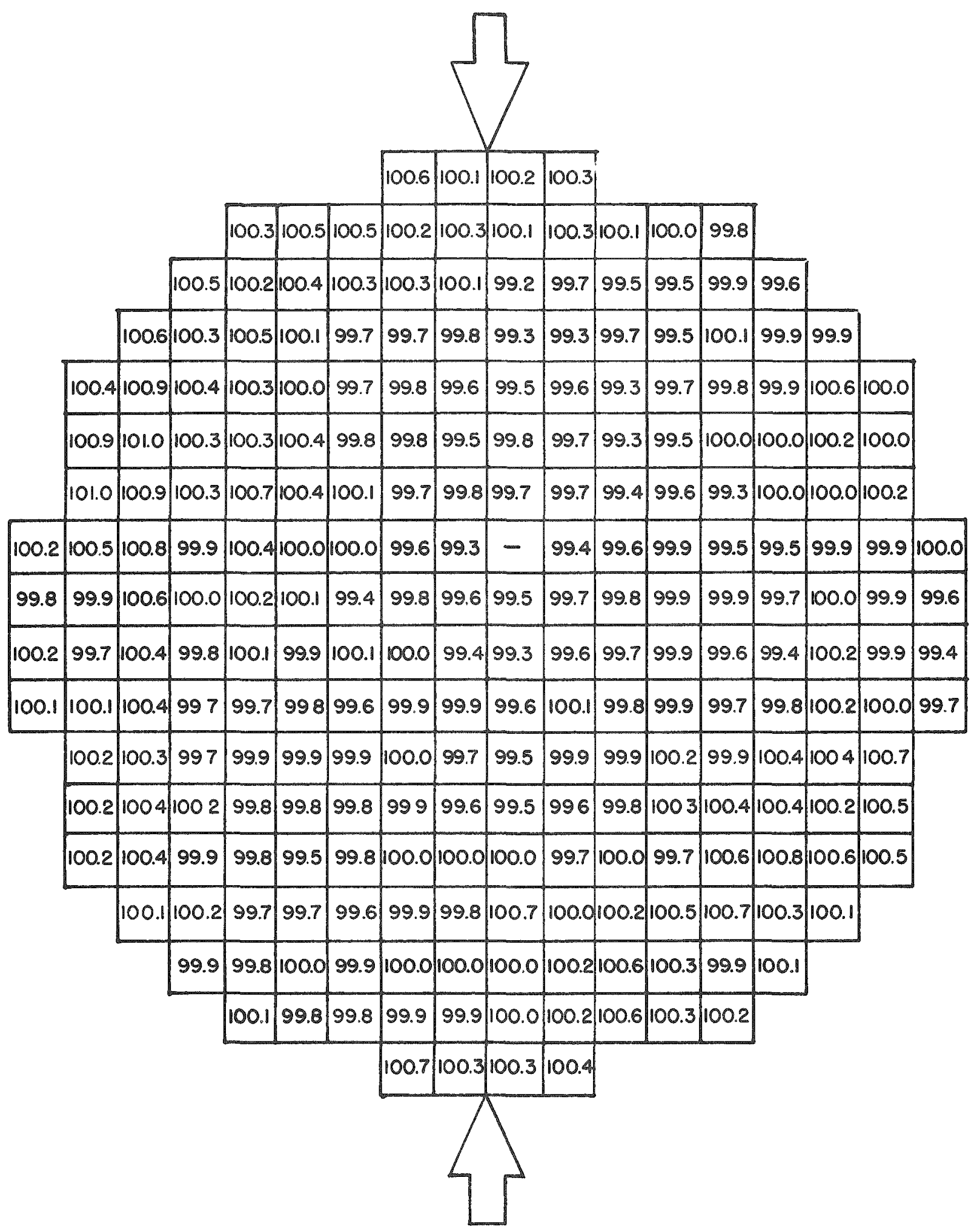

FIGURE 5. DISTRIBUTION OF FLOW IN CORE OF MODEL WITH TWO LOOPS OPERATING

Number in each simulated fuel channel shows percentage of average flow for the core. 


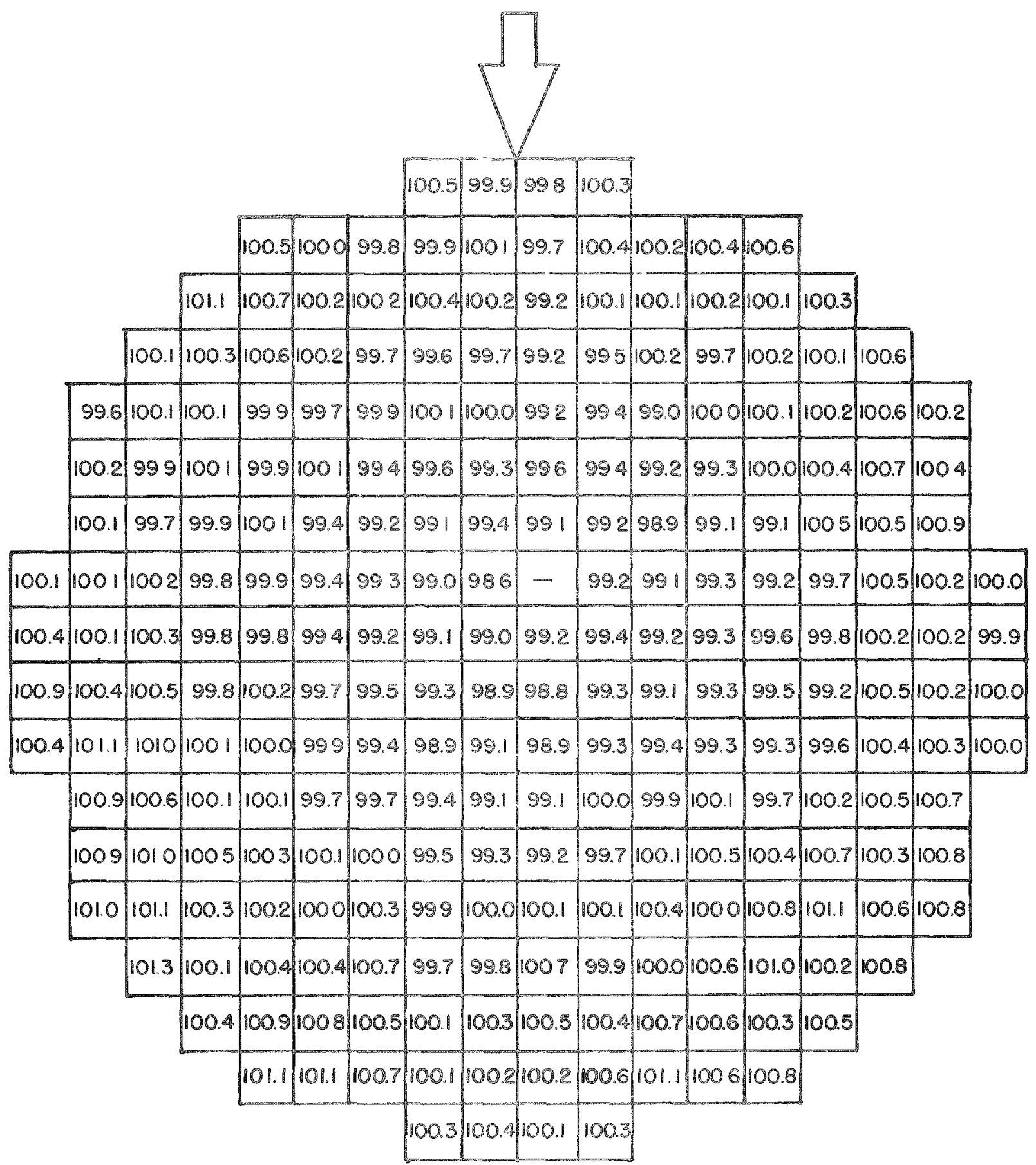

FIGURE 6. DISTRIBUTION OF FIOW IN CORE OF MODEL WITH OIVE LOUP OPERATING

Number in each simulated fuel channel shows percentage of avouge flow for the core. 
traverse the entire core in about 1 day with frequent checks of inlet concentration and of background level in the second inlet, which nominally contained no $\mathrm{SO}_{2}$.

The Titrilog, which was used to measure $\mathrm{SO}_{2}$ concentration, is manufactured by the Consolidated Electrodynamics Corporation. In this instrument, $\mathrm{SO}_{2}$ is titrated with electrolytically generated bromine at a potentiometric balance point. A feedback amplifier controls the rate of generation of reacting bromine above a set reference level so that it is at all times equal to the rate of absorption of $\mathrm{SO}_{2}$ in the titration cell. The current flow in the titration cell serves as a measure of $\mathrm{SO}_{2}$ concentration. The instrument scale has a range of 0 to 10 ppm of $S_{2}$ with a reading accuracy of \pm 1.5 per cent of full-scale reading. The threshold sensitivity is 0.1 ppm; about 10 sec is required to reach equilibrium after a change in concentration.

The Titrilog and associated gas-control equipment are shown on the table in Figure 1. Directly above the Titrilog, at the top of the figure, is the $\mathrm{SO}_{2}$ injector installed in the Loop 1 inlet piping.

Figure 7 shows mixing data obtained with $\mathrm{SO}_{2}$ injected into the inlet of Loop 1. The figure represents a cross section of the core of the flow model with numbers indicating the percentage of flow in each simulated fuel channel coming from Inlet 1 , the traced inlet. With perfect mixing in the lower plenum a value of 50 per cent would be obtained in every channel. It will be noted, however, that the highest concentrations were found near the traced inlet and that concentrations decreased with distance from the inlet. A maximum value of 76 per cent was found.

\section{Studies of Thermal-Shield-Coolant Flow}

As shown in Figure 2, the thermal shield is a heavy liner separated from the pressure vessel by a coolant passage which, in the model, is $0.25 \mathrm{in}$. wide. The prototype shield is heated by core radiation and by heat transfer from the $1200 \mathrm{~F}$ helium in the upper plenum, and cooled by helium admitted through annular passages surrounding each of the 32 flux-scanning nozzles and 29 control-rod nozzles located near the center of the top dome. This passes downward through the shield-coolant channel to the inlet plenum and mixes with helium from the inlets. The shield coolant is supplied from an external system in which it is cooled and decontaminated. In order to avoid local overheating and resulting distortion of the thermal shield, it is necessary that the entire surface be swept by coolant at adequate velocity. Accordingly, flow velocities and directions throughout the coolant passage were studied.

Dynamic similarity in shield-passage studies requires special consideration because of the range of Reynolds numbers involved. Prototype values of Reynolds numbers vary from 5000 to 7000 if shield coolant is 2.5 and 3.5 per cent of reactor flow, respectively. These percentages of model flow result in model Reynolds numbers of 2000 and 2800, which are in the transition range. Accordingly, model studies were carried out at both the proper percentages of total flow above, and at higher flow rates providing full prototype Reynolds numbers. It was found that flow patterns varied with shield-coolant flow rate, because of interaction between the shield flow and flow passing upward into the shield passage from the inlet plenum. A stagnation region was found in every test. The location of this stagnation region varied with the amount of shieldcoolant flow; with high flow rates the stagnation region was near the bottom of the shield passage, and with low flow rates it was near the top of the passage. The nature of the 
traverse the entire core in about 1 day with frequent checks of inlet concentration and of background level in the second inlet, which nominally contained no $\mathrm{SO}_{2}$.

The Titrilog, which was used to measure $\mathrm{SO}_{2}$ concentration, is manufactured by the Consolidated Electrodynamics Corporation. In this instrument, $\mathrm{SO}_{2}$ is titrated with electrolytically generated bromine at a potentiometric balance point. A feedback amplifier controls the rate of generation of reacting bromine above a set reference level so that it is at all times equal to the rate of absorption of $\mathrm{SO}_{2}$ in the titration cell. The current flow in the titration cell serves as a measure of $\mathrm{SO}_{2}$ concentration. The instrument scale has a range of 0 to $10 \mathrm{ppm}$ of $\mathrm{SO}_{2}$ with a reading accuracy of \pm 1.5 per cent of full-scale reading. The threshold sensitivity is $0.1 \mathrm{ppm}$; about $10 \mathrm{sec}$ is required to reach equilibrium after a change in concentration.

The Titrilog and associated gas-control equipment are shown on the table in Figure 1. Directly above the Titrilog, at the top of the figure, is the $\mathrm{SO}_{2}$ injector installed in the Loop 1 inlet piping.

Figure 7 shows mixing data obtained with $\mathrm{SO}_{2}$ injected into the inlet of Loop 1 . The figure represents a cross section of the core of the flow model with numbers indicating the percentage of flow in each simulated fuel channel coming from Inlet 1 , the traced inlet. With perfect mixing in the lower plenum a value of 50 per cent would be obtained in every channel. It will be noted, however, that the highest concentrations were found near the traced inlet and that concentrations decreased with distance from the inlet. A maximum value of 76 per cent was found.

\section{Studies of Thermal-Shield-Coolant Flow}

As shown in Figure 2, the thermal shield is a heavy liner separated from the pressure vessel by a coolant passage which, in the model, is 0.25 in. wide. The prototype shield is heated by core radiation and by heat transfer from the $1200 \mathrm{~F}$ helium in the upper plenum, and cooled by helium admitted through annular passages surrounding each of the 32 flux-scanning nozzles and 29 control-rod nozzles located near the center of the top dome. This passes downward through the shield-coolant channel to the inlet plenum and mixes with helium from the inlets. The shield coolant is supplied from an external system in which it is cooled and decontaminated. In order to avoid local overheating and resulting distortion of the thermal shield, it is necessary that the entixe surface be swept by coolant at adequate velocity. Accordingly, flow velocities and directions throughout the coolant passage were studied.

Dynamic similarity in shield-passage studies requires special consideration because of the range of Reynolds numbexs involved. Prototype values of Reynolds numbers vary from 5000 to 7000 if shield coolant is 2.5 and 3.5 per cent of reactor flow, respectively. These percentages of model flow result in model Reynolds numbers of 2000 and 2800, which are in the transition range. Accordingly, model studies were carried out at both the proper percentages of total flow above, and at higher flow rates providing full prototype Reynolds numbers. It was found that flow patterns varied with shield-coolant flow rate, because of interaction between the shield flow and flow passing upward into the shield passage from the inlet plenum. A stagnation region was found in every test. The location of this stagnation region varied with the amount of shieldcoolant flow; with high flow rates the stagnation region was near the bottom of the shield passage, and with low flow rates it was near the top of the passage. The nature of the 


\begin{tabular}{|c|c|c|c|c|c|c|c|c|c|c|c|c|c|c|c|c|c|}
\hline & & & & & & & & & & Tro & ced & Inlet & & & & & \\
\hline & & & & & & & 62 & 66 & 72 & 71 & & & & & & & \\
\hline & & & & 61 & 59 & 57 & 61 & 66 & 71 & 73 & 76 & 73 & 72 & & & & \\
\hline & & & 66 & 59 & 58 & 58 & 62 & 66 & 65 & 69 & 73 & 71 & 75 & 73 & & & \\
\hline & & 71 & 68 & 65 & 61 & 54 & 58 & 61 & 65 & 68 & 72 & 72 & 73 & 76 & 76 & & \\
\hline & 66 & 68 & 73 & 59 & 57 & 57 & 58 & 61 & 62 & 64 & 71 & 68 & 71 & 72 & 72 & 73 & \\
\hline & 71 & 72 & 72 & 62 & 59 & 58 & 59 & 62 & 62 & 62 & 69 & 69 & 69 & 71 & 66 & 66 & \\
\hline & 66 & 66 & 61 & 59 & 61 & 57 & 59 & 59 & 55 & 58 & 64 & 64 & 68 & 66 & 65 & 62 & \\
\hline 59 & 58 & 58 & 57 & 59 & 59 & 55 & 52 & 52 & 45 & 47 & 52 & 52 & 55 & 54 & 55 & 51 & 68 \\
\hline 62 & 58 & 59 & 54 & 57 & 57 & 51 & 51 & 48 & 47 & 42 & 45 & 44 & 47 & 48 & 47 & 41 & 54 \\
\hline 57 & 55 & 57 & 51 & 54 & 54 & 51 & 49 & 47 & 44 & 40 & 40 & 42 & 41 & 40 & 44 & 40 & 49 \\
\hline 44 & 44 & 48 & 45 & 49 & 49 & 48 & 48 & 48 & 42 & 38 & 34 & 40 & 37 & 35 & 42 & 42 & 41 \\
\hline & 37 & 37 & 31 & 34 & 38 & 40 & 45 & 42 & 37 & 37 & 37 & 40 & 37 & 31 & 37 & 34 & \\
\hline & 32 & 34 & 31 & 27 & 31 & 37 & 44 & 40 & 37 & 38 & 38 & 35 & 34 & 32 & 34 & 30 & \\
\hline & 31 & 28 & 25 & 25 & 27 & 32 & 44 & 40 & 41 & 44 & 41 & 41 & 37 & 35 & 31 & 37 & \\
\hline & & 25 & 24 & 27 & 28 & 28 & 38 & 35 & 34 & 40 & 42 & 45 & 40 & 32 & 31 & & \\
\hline & & & 24 & 27 & 28 & 31 & 37 & 38 & 37 & 44 & 48 & 47 & 38 & 34 & & & \\
\hline & & & & 25 & 30 & 31 & 35 & 35 & 38 & 41 & 44 & 41 & 37 & & & & \\
\hline & & & & & & & 32 & 32 & 34 & 38 & & & & & & & \\
\hline
\end{tabular}

FIGURE 7. MIXING IN LOWER PLENUM OF MODEL

Number in each simulated fuel channel shows percentage of air from Inlet 1 the traced inlet. 
stagnation region, and its effects on local heat transfer, appeared similar for all flow rates. Thus, the test condition most closely representing the actual flow and velocity distribution in the thermal-shield-coolant passage appears to be that in which the proportion of total model flow passing through the shield passage is equal to that for the prototype.

In the model studies, shield-passage air was supplied by an air compressor, so that flow rate could be varied. Air velocities and directions in the shield passage were measured using a three-hole yaw probe, but in earlier tests it was found that neither velocities nor directions of flow could be measured in the stagnation regions. This was partly because all velocities were so low as to be near the lower limit of sensitivity of the yaw probe, and partly because velocities were in the form of local turbulence which was variable in direction. A hot-wire anemometer probe of high sensitivity and having a directional characteristic was made and used for subsequent tests at the higher flow rates. With this probe it was possible to measure turbulence levels in the stagnation regions equivalent to substantial velocities, but no directional effects could be observed.

Figure 8 is a data plot showing the directions and velocities of air flow in the thermal-shield-coolant passage with two loops operating. The shield-flow rate was 8.5 per cent of the total model flow rate, so that the Reynolds number in the model shield passage was equal to that for the prototype with 3.5 per cent of reactor flow passing through the shield passage. Arrows are at yaw-probe locations and indicate flow directions; numbers indicate flow velocities. Velocities of helium flow in the prototype are 0.266 times the air-flow velocities shown. As can be seen in the figure, flow is downward everywhere except for stagnation regions immediately above the inlets, where upward flow from the inlet plenum meets downward flow in the shield passage.

Figure 9 shows the flow pattern in the shield pas sage with two loops operating with 6.4 per cent of model flow passing through the shield passage to provide a model Reynolds number equal to that in the prototype with $2-1 / 2$ per cent shield flow. Velocities in the prototype shield passage are 0.244 times those shown. The flow is downward everywhere with a uniform velocity except in the stagnation regions directly above the inlets where upward flow from the inlet meets downward flow in the shield passage. Yaw-probe readings could not be obtained at the two measuring points above the inlets due to rapidly fluctuating flow directions.

A comparison of Figures 8 and 9 shows that the change in Reynolds number did not affect shield-coolant-flow patterns except near the inlets, where the change in downward velocity changed the locations of the stagnation regions separating upward and downward flow; this would appear to be a momentum effect dependent upon the relative velocities of upward and downward flow, rather than a Reynolds number effect.

Figure 10 shows flow directions and velocities in the shield-coolant passage for one-1oop operation with 12 per cent of model flow though the shield passage. At this flow condition the model Reynolds number is equal to the prototype Reynolds number with 7 per cent shield flow. With only one loop operating, flow directions throughout the shield passage are affected by the upward flow from the operating inlet and the area of upward flow extended more than halfway up the cylindrical portion of the passage.

From these studies it was apparent that additional tests with the shield-flow rate at the proper percentages of model flow rate were needed. In this case the shield Reynolds number would be about 30 to 40 per cent of prototype value for two-loop 


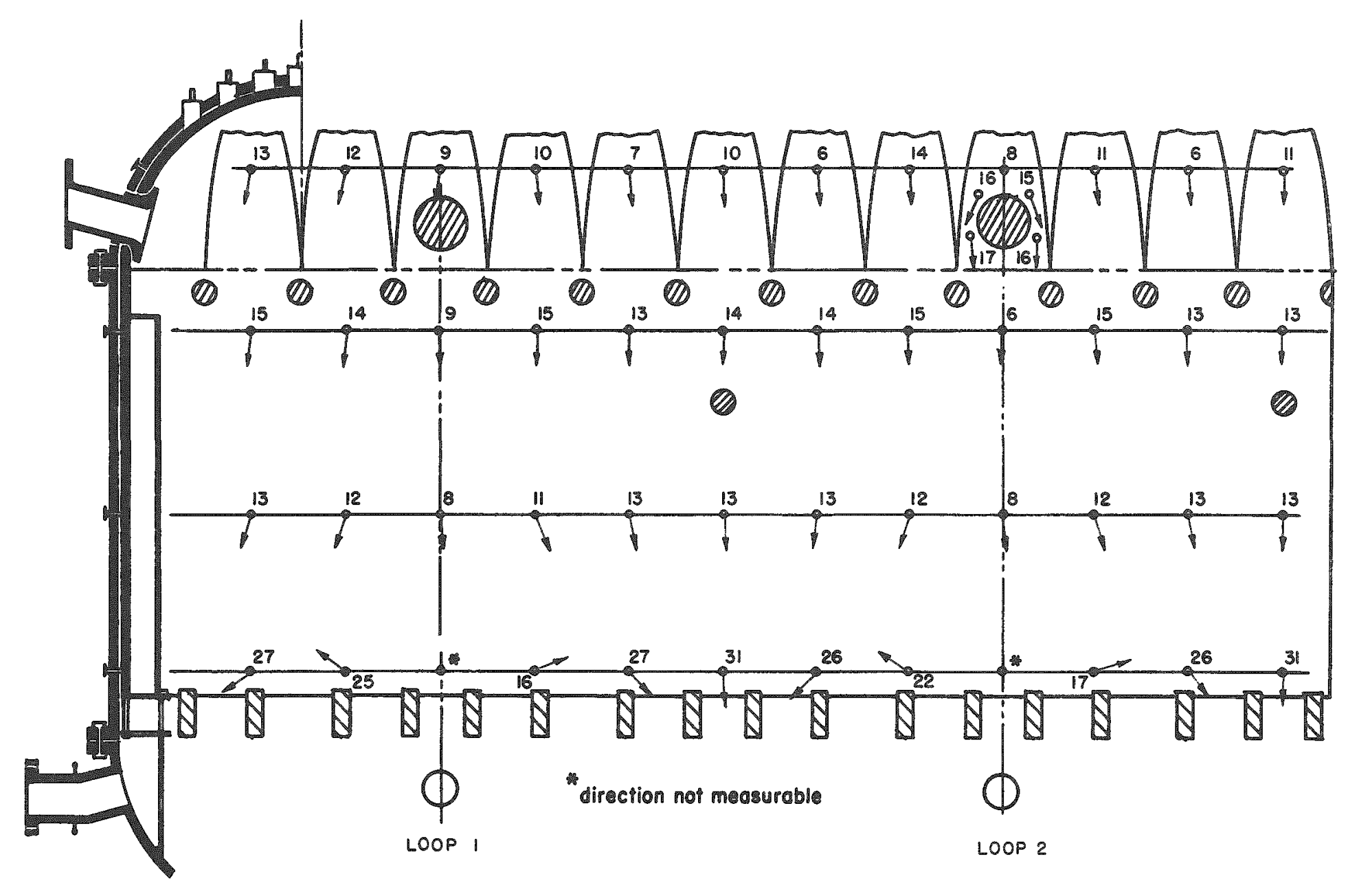

FIGURE 8. FLOW PATTERNS IN THERMAL-SHIELD-COOLANT PASSAGE WITH FLOW RATE OF 8.5 PER CENT OF MODEL FLOW FOR TWO-LOOP OPERATION

Arrows indicate flow direction and numbers indicate air velocity, fps.

Heliun velocities are 0.260 tines air velocities. 


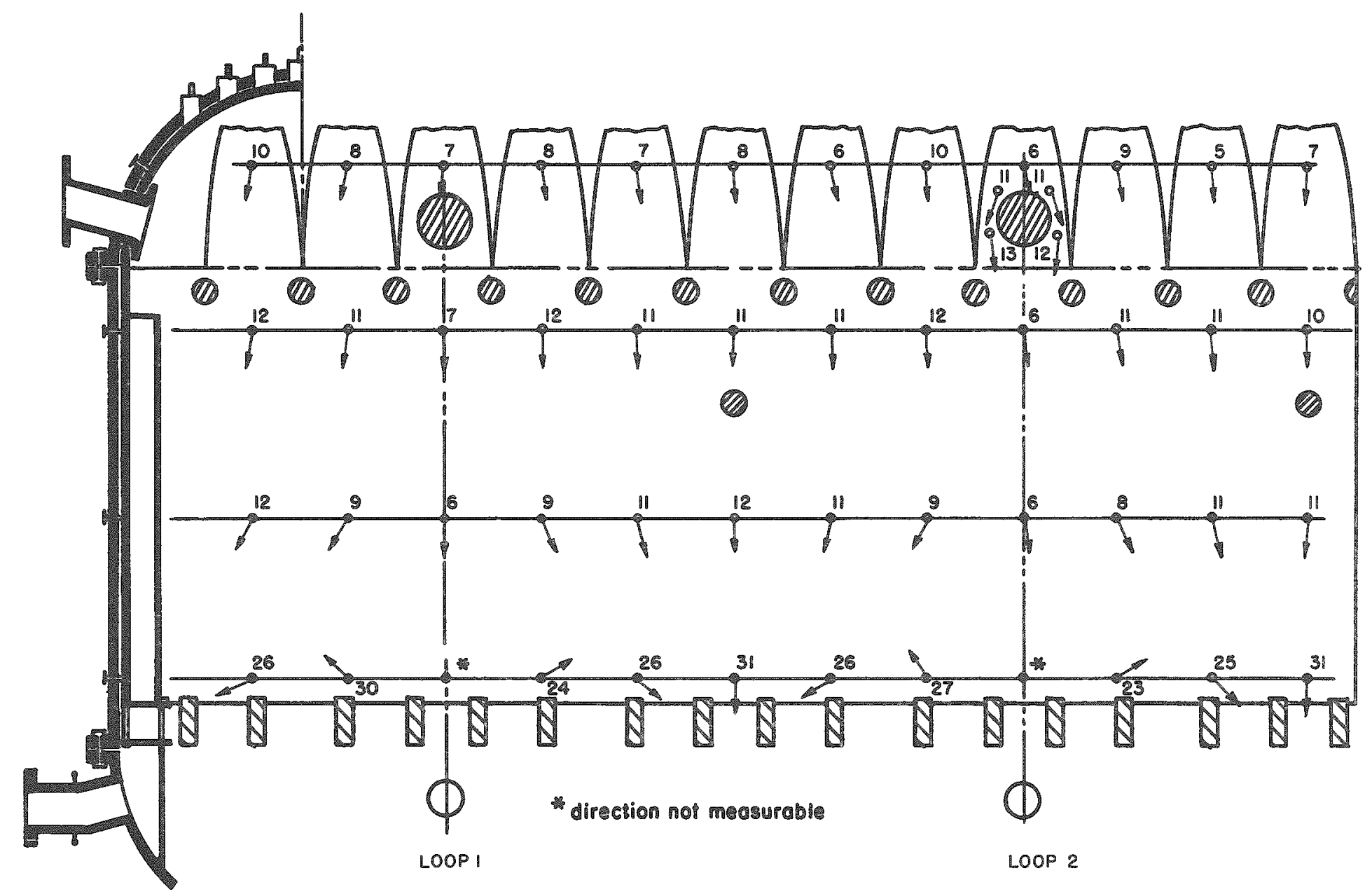

FIGURE 9. FLOW PATTERNS IN THERMAL-SHIELD-COOLANT PASSAGE WITH FLOW RATE OF 6.4 PER CENT OF MODEL FLOW FOR TWO-LOOP OPERATION

Arrows indicate flow direction and numbers indicate air velocity, fps.

Helium velocities are 0.244 times air velocities. 


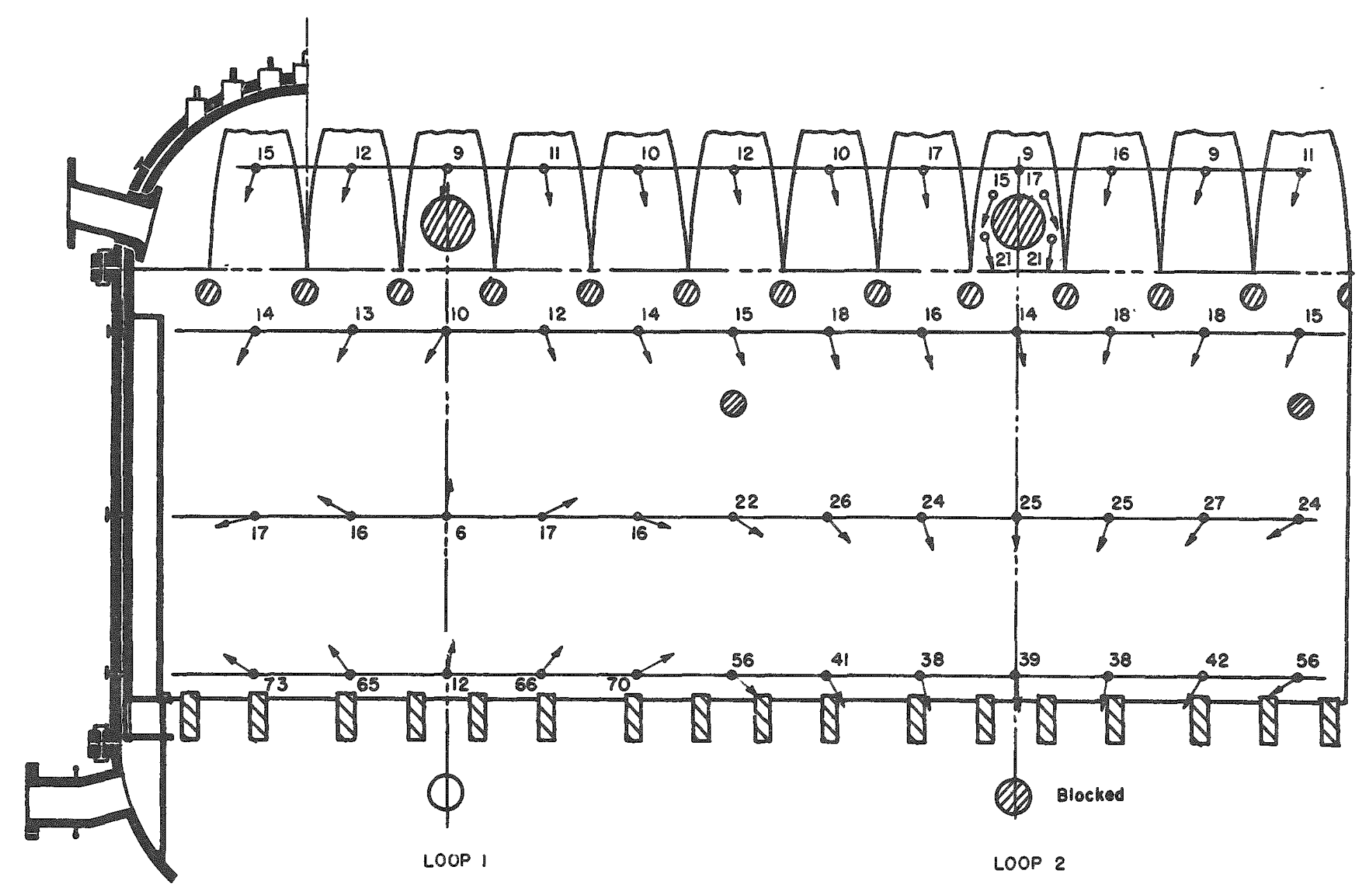

FIGURE 10. FLOW PATTERNS IN THERMAL-SHIELD-COOLANT PASSAGE WITH FLOW RATE OF 12.0 PER CENT OF MODEL FLOW FOR ONE-LOOP OPERATION

Arrows indicate flow direction and numbers indicate air velocity. fps.

Helium velocities are 0.246 times air velocities. 
operation and about 60 per cent of prototype value for one-loop operation, and would range from 2000 to 2800 .

Figures $11,12,13$, and 14 show shield-flow patterns with shield-flow rates of $2-1 / 2$ and $3-1 / 2$ per cent of model flow. To more fully explore the areas where upward flow occurred, 24 additional yaw-probe holes were added in the model. Flow velocities and directions were measured, where possible, with three-hole yaw probes, but at some locations no yaw-probe reading could be obtained due to rapidly fluctuating flow directions. At these points, velocities were measured with a specially built hot-wire anemometer; in most cases no flow direction could be determined. The minimum velocity measured at any point was 2.5 fps which occurred with a shield-flow rate of $2-1 / 2$ per cent of model flow with two loops operating. This is equivalent to a helium velocity of $1.6 \mathrm{fps}$ in the prototype.

From the studies with model shield Reynolds numbers equal to prototype-shield Reynolds numbers it was found that half-symmetry existed. Therefore in the shield studies made with the correct percentage shield-flow data were taken at only half the shield measuring points. Measured data are shown as solid arrows. The dotted arrows show assumed velocities, based on half-symmetry, where velocities were not measured.

Figure 11 is a development of the thermal-shield passage showing the directions and velocities of air flow with a shield-flow rate of $2-1 / 2$ per cent of model flow with wo loops operating. The upward flow area extends about three-fourths the height of the core. Flow directions could not be determined at the measuring locations shown without arrows. The minimum turbulence level measured in the stagnation area was equivalent to a velocity of $2.5 \mathrm{fps}$ which is equivalent to a helium velocity of $1.6 \mathrm{fps}$.

Figure 12 shows the flow patterns obtained with a shield-flow rate of $3-1 / 2$ per cent of model flow for two-loop operation. As with $2-1 / 2$ per cent flow all areas appeared to be adequately cooled.

Figure 13 shows flow directions and velocities for one-1oop operation with shield flow of 3-1/2 per cent of model flow. The area of upward flow extended up to the outlet nozzle. The minimum turbulence level measured in the stagnation area was equivalent to a helium velocity of $0.9 \mathrm{fps}$ based on an assumed one-10op flow rate of $2.135 \times 10^{5} \mathrm{lb}$ per hr.

Figure 14 shows the coolant-passage-flow patterns obtained with a shield flow rate of 2-1/2 per cent of model flow for one-1oop operation. The area of upward flow over the open inlet extended up to the center line of the outlet nozzle. The minimum turbulence level measured was equivalent to a helium velocity of $0.8 \mathrm{fps}$.

Comparison of Figures 8, 9, and 10 with Figures 11, 12, and 13 shows that the flow pattern in the thermal-shield passage are probably not appreciably affected by Reynolds number even though they were in the transition range. The shift of the elevation of the stagnation regions, where upward flow trom the inlets meets downward flow in the shield passage, appears to be a momentum effect. The downward velocity of the shield coolant appears to have a much greater effect than any variations in shieldpassage friction which might occur in the transition range. 


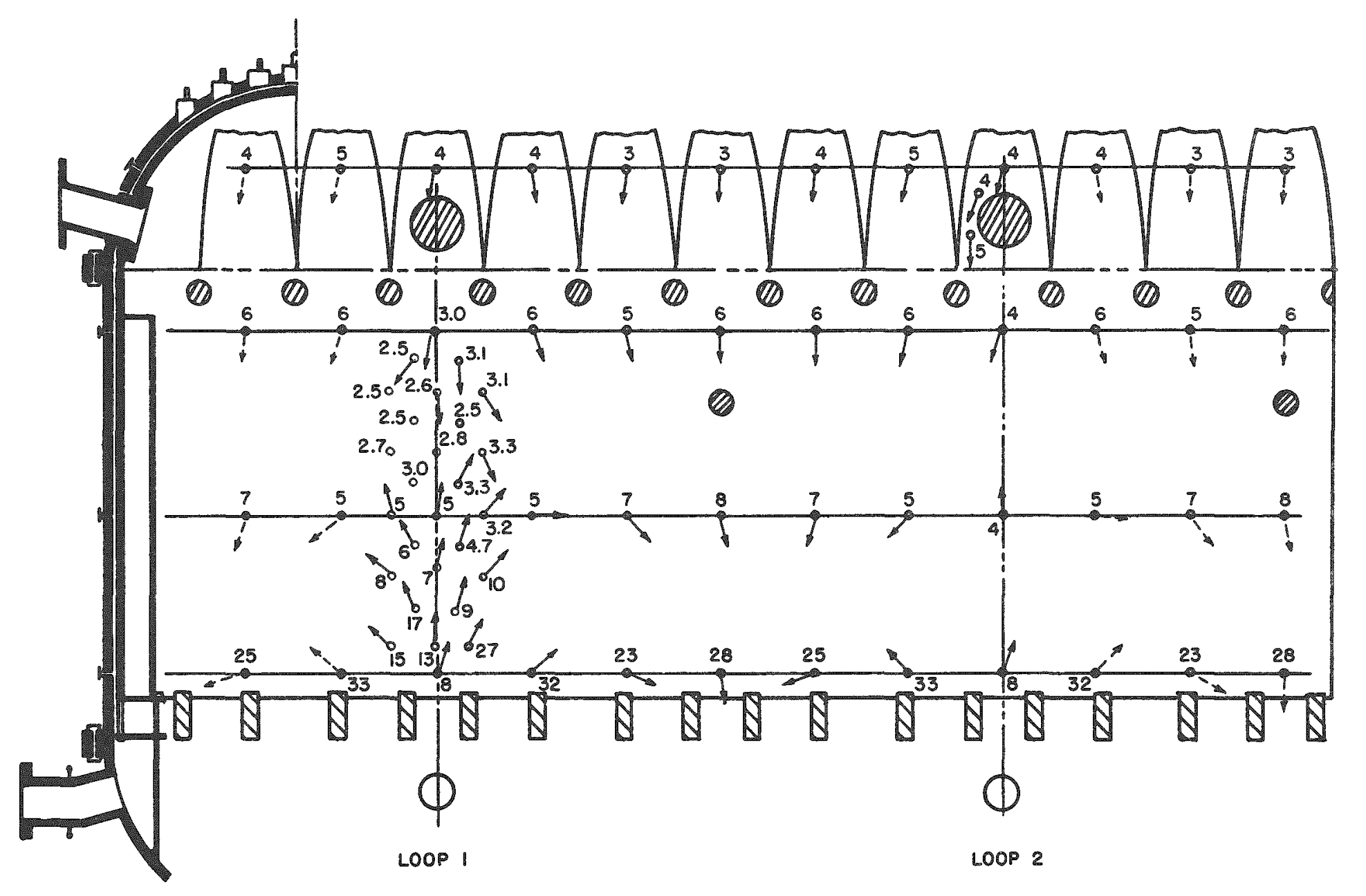

FIGURE 11. FLOW PATTERNS IN THERMAL-SHIELD-COOLANT PASSAGE WITH ELOW RATE OF 2-1/2 PER CENT OF MODEL FLOW FOR TWO-LOOP OPERATION

Arrows indicate flow direction and numbers indicate air velocity, fps.

Helium velocities are 0.63 times air velocities. 


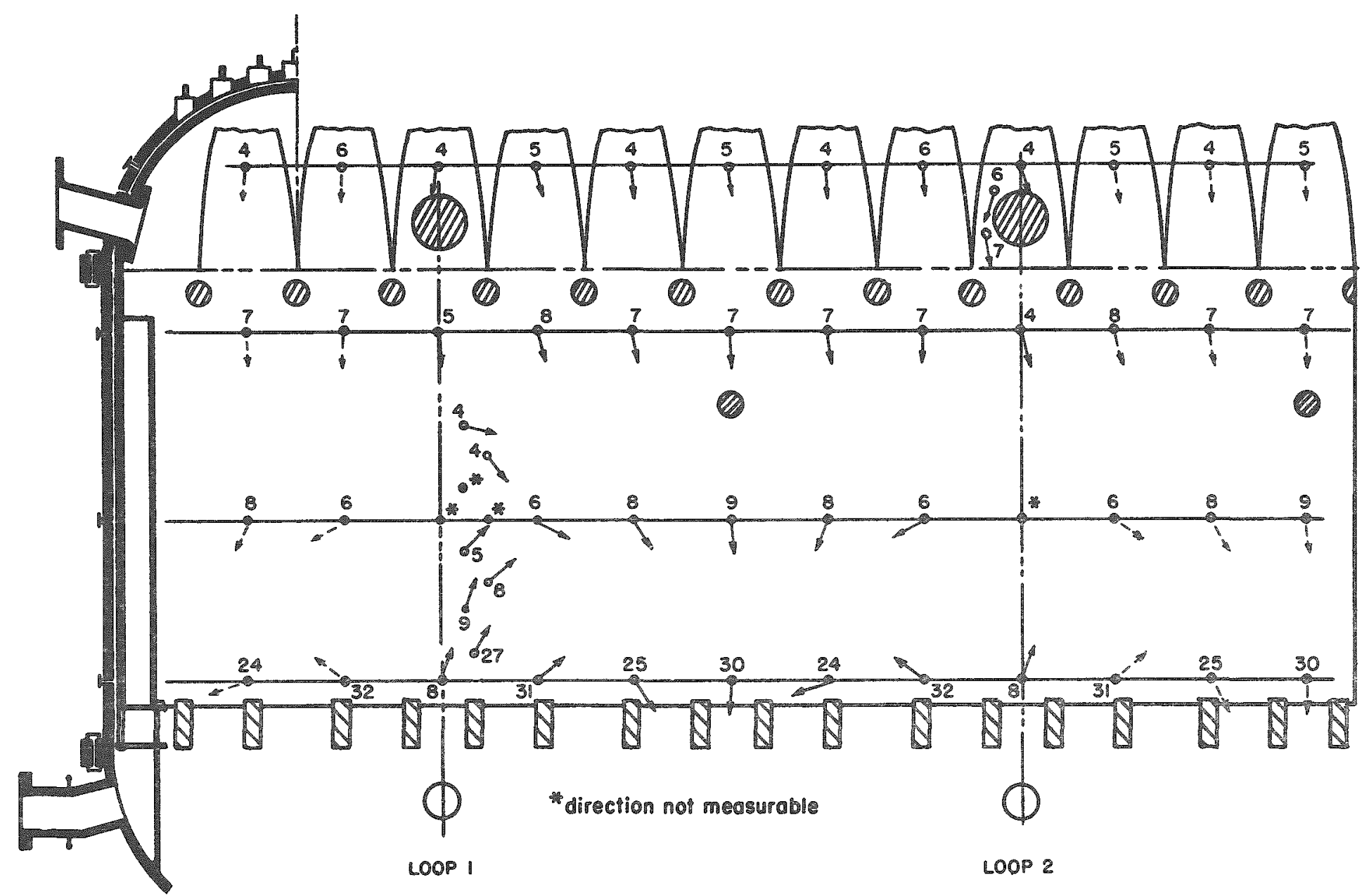

FIGURE 12. FLOW PATTERINS IN THERMAL-SHIELD-COOLANT PASSAGE WITH FLOW RATE OF 3-1/2 PER CENT OF MODEL FLOW FOR TWO-LOOP OPERATION

Arrows indicate flow direction and numbers indicate air velocity, fps.

Helium velocities are 0.66 times air velocities. 


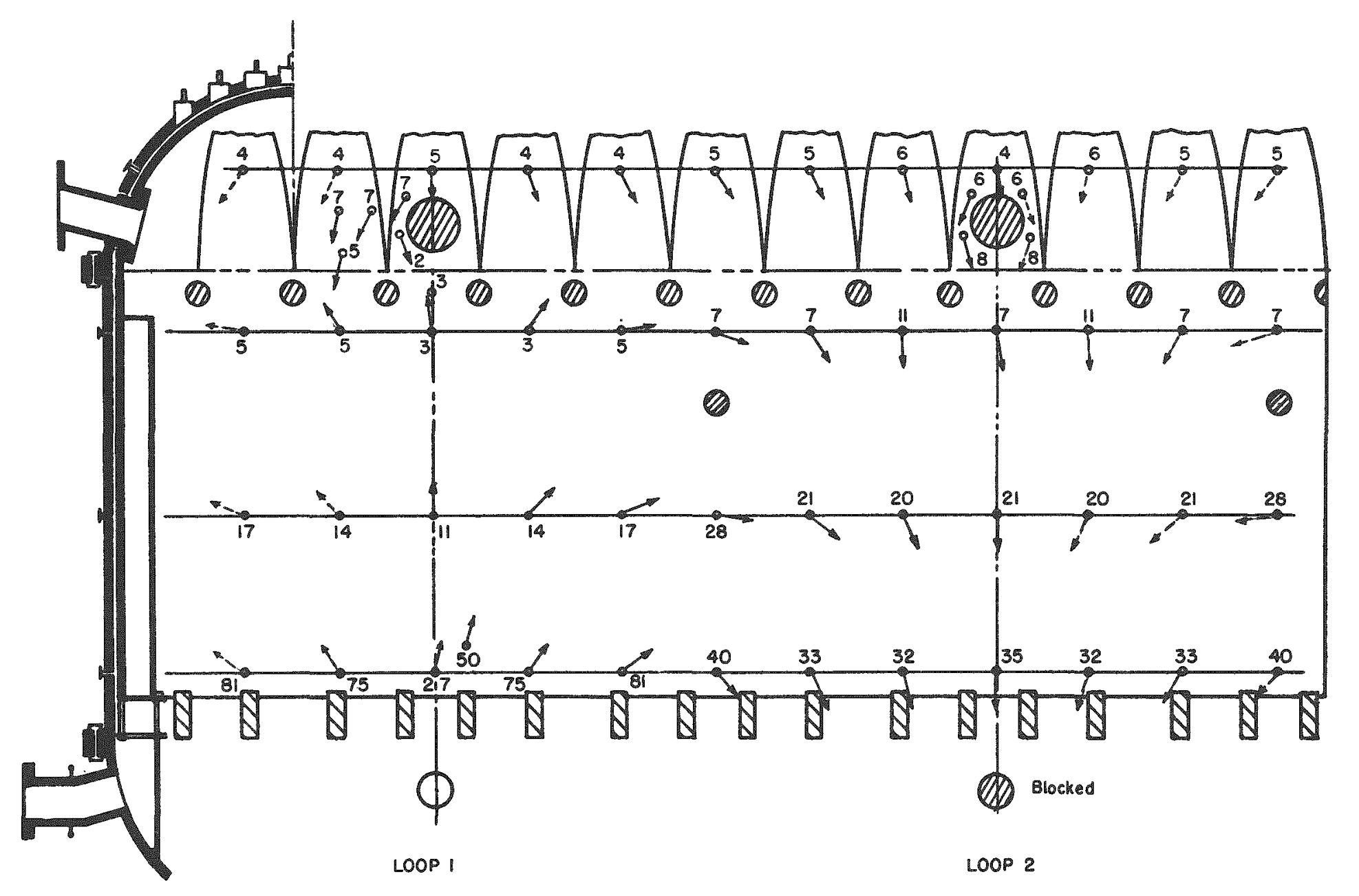

FIGURE 13. FLOW PATTERNS IN THERMAL-SHIELD-COOLANT PASSAGE WITH FLOW RATE OF 3-1/2 PER CENT OF MODEL FLOW FOR ONE-LOOP OPERATION

Arrows indicate flow direction and numbers indicate air velocity, fps.

Helium velocities are 0.40 times air velocities. 


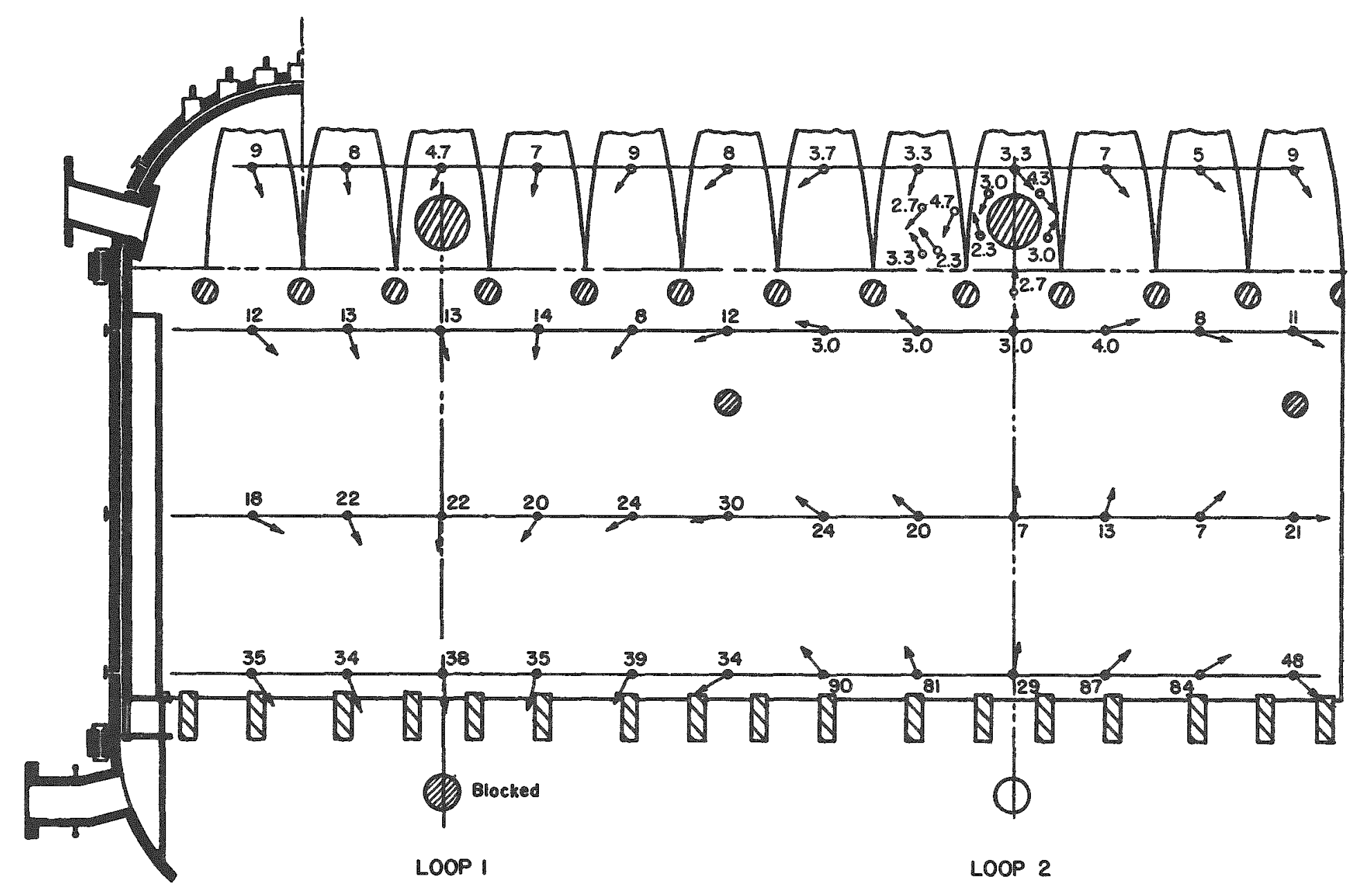

FIGURE 14. FLOW PATTERNS IN THERMAL-SHIELD-COOLANT PASSAGE WITH FLOW RATE OF 2-1/2 PER CENT OF MODEL FLOW FOR ONE-LOOP OPERATION

Arrows indicate flow direction and numbers indicate air velocity, fps.

Helium velocities are 0.34 times air velocities. 
Upper-Plenum Studies

Upper-plenum flow was studied for both one-loop and two-loop operation to determine the flow patterns in the upper plenum and the velocities at the inner surface of the thermal shield. The flow patterns were determined by visual observation using $\mathrm{TiCl}_{4}$ smoke as a tracer. Air velocities near the surface of the dome were measured using a three-hole yaw probe of conventional design.

Figure 15 shows the flow patterns in the upper plenum of the model with two loops operating. The diagram in the upper right corner is a development of one quadrant of the dome showing flow directions and velocities measured $1 / 4 \mathrm{in}$. from the inner surface of the thermal shield. From the figure it can be seen that the flow in the upper plenum has a toroidal pattern with flows upward in the center and down near the wall. Superimposed on this is a slight clockwise (looking down) rotation probably carried up through the core from the lower plenum. As a result, a large part of the flow takes a helical path into the outlets. Velocities were measured near the surface of the top dome at six locations in one quadrant. Air velocities measured 1/4 in. from the wall varied from 35 to $69 \mathrm{fps}$. The corresponding helium velocities in the prototype would be 0.835 times these values, ranging from 29 to $58 \mathrm{fps}$. The smoke studies also showed that the maximum velocity sweeping the wall occurred in the quadrant where measurements were made.

Figure 16 shows the flow patterns obtained in the upper plenum with one loop operating. Looking down, the fluid in the quadrant adjacent to, and clockwise from the operating outlet flowed directly into the outlet. Fluid in the remaining three quadrants flowed clockwise around the plenum into the outlet in a torodial pattern. As for two-loop operation, the highest surface velocities occurred in the quadrant where measurements were made. The air velocities varied from 22 to $43 \mathrm{fps}$ measured $1 / 4 \mathrm{in}$. from the wall. The corresponding helium velocities would be 0.57 times the air velocities, and would range from 13 to $25 \mathrm{fps}$.

\section{Lowex-Plenum Studies}

Velocity and direction of flow were measured in the inlet plenum and the lower plenum near the junction of the core-support cylinder and the bottom dome for operation with one loop and two loops. These studies were run to obtain surface velocities near this junction, which are needed to compute heat-transfer rates and resulting thermal stresses in the junction region.

Figures 17 and 18 show a cross section of the bottom of the modeland developments of the inner surface of the bottom dome and the outside of the core-support cylindex. The data were obtained with conventional three-hole yaw probes at a distance of $1 / 4 \mathrm{in}$. from the surfaces. In the figures, arrows are at yaw-probe locations and indicate flow directions; numbers indicate flow velocities.

Figure 17 shows the flow patterns obtained with two loops operating. In the inlet plenum, air velocities varied from $88 \mathrm{fps}$ on the surface of the core-support cylinder to $15 \mathrm{fps}$ near the right inlet. In the lower plenum the velocity varied from 27 to $15 \mathrm{fps}$. The ratio of helium velocity to model air velocity is 0.61 . 


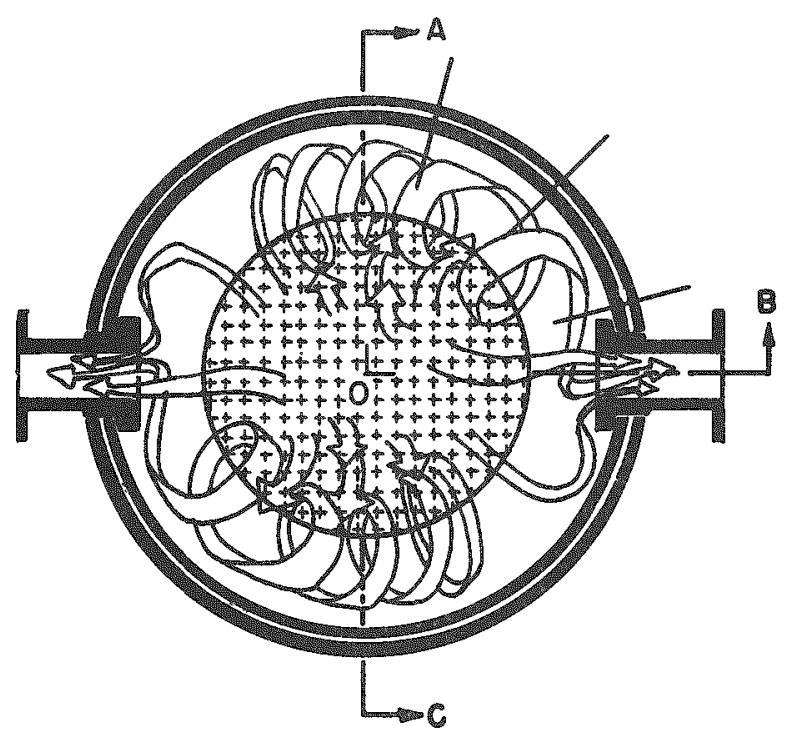

Top View

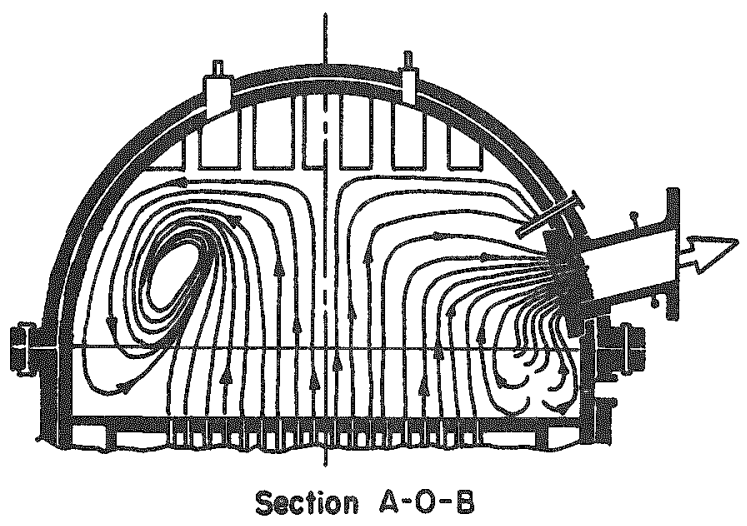

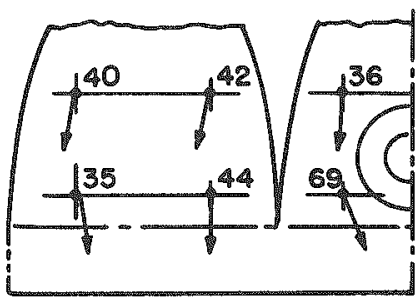

Quodrant $A-B$

Surfoce Velocity, pos

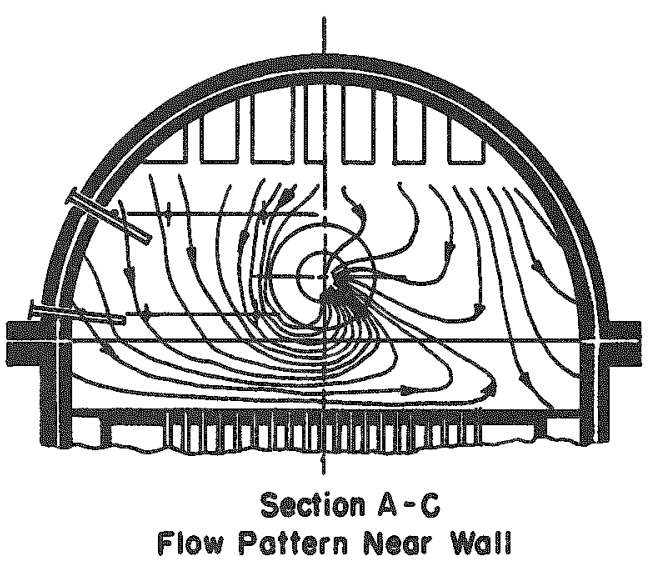

FIGURE 15. FLOW PATTERNS IN UPPER PLENUM WITH TWO LOOPS OPERATING

Arrows indicate flow direction and numbers indicate air velocity, fps.

Helium velocities are 0.835 times air velocities. 


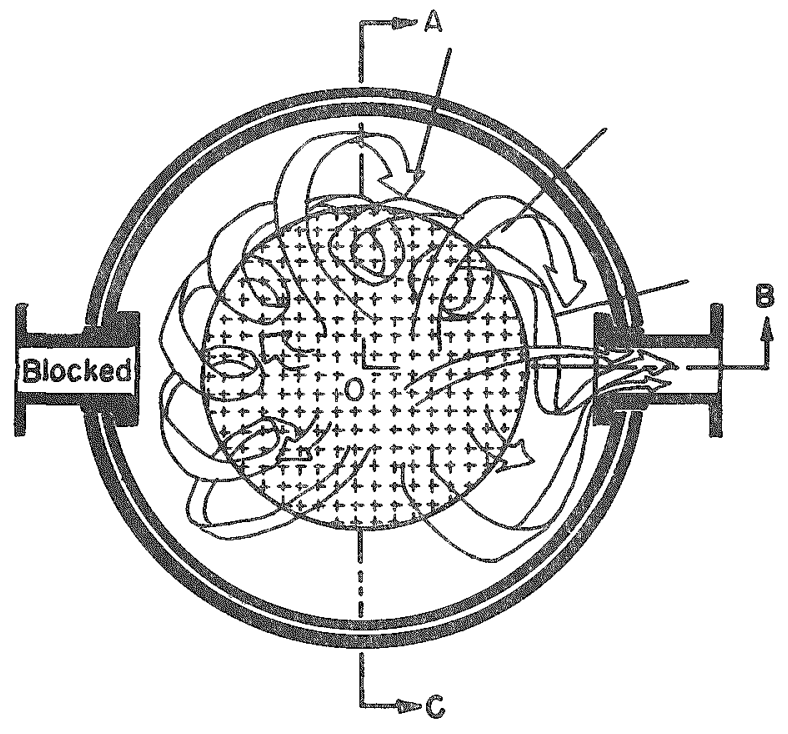

Top Vism

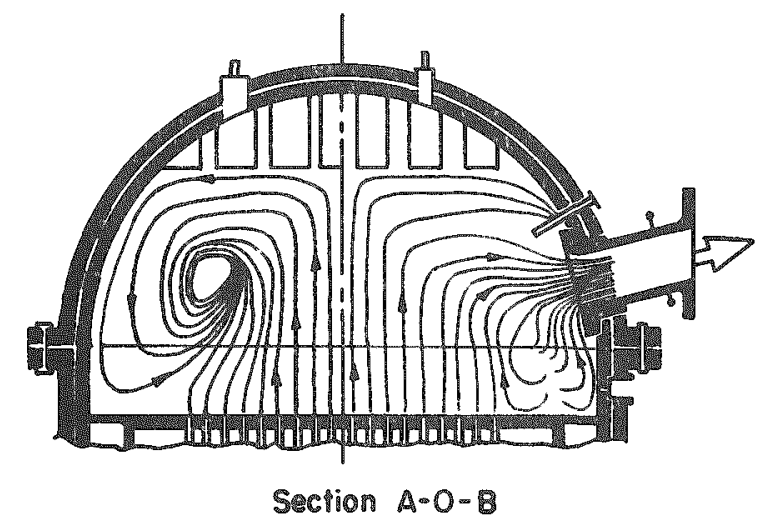

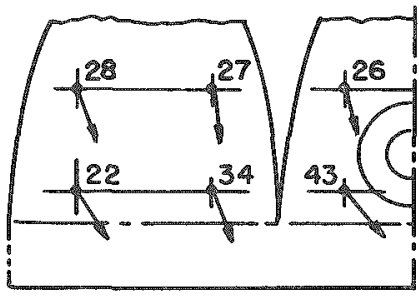

Quodront 4 Surfoce Velocities, Pps

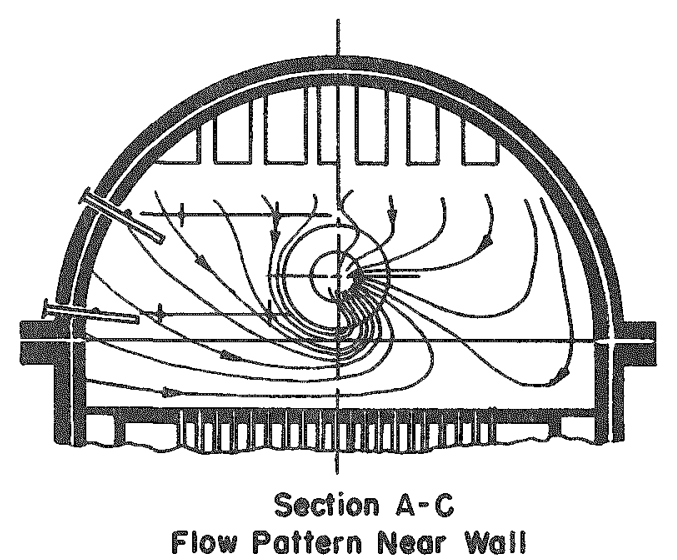

FIGURE 16. FLOW PATTERNS IN UPPER PLENUM WITH ONE LOOP OPERATING

Arrows indicate flow direction and numbers indicate air velocity, fps.

Ielium velocities are 0.57 times air velocities. 


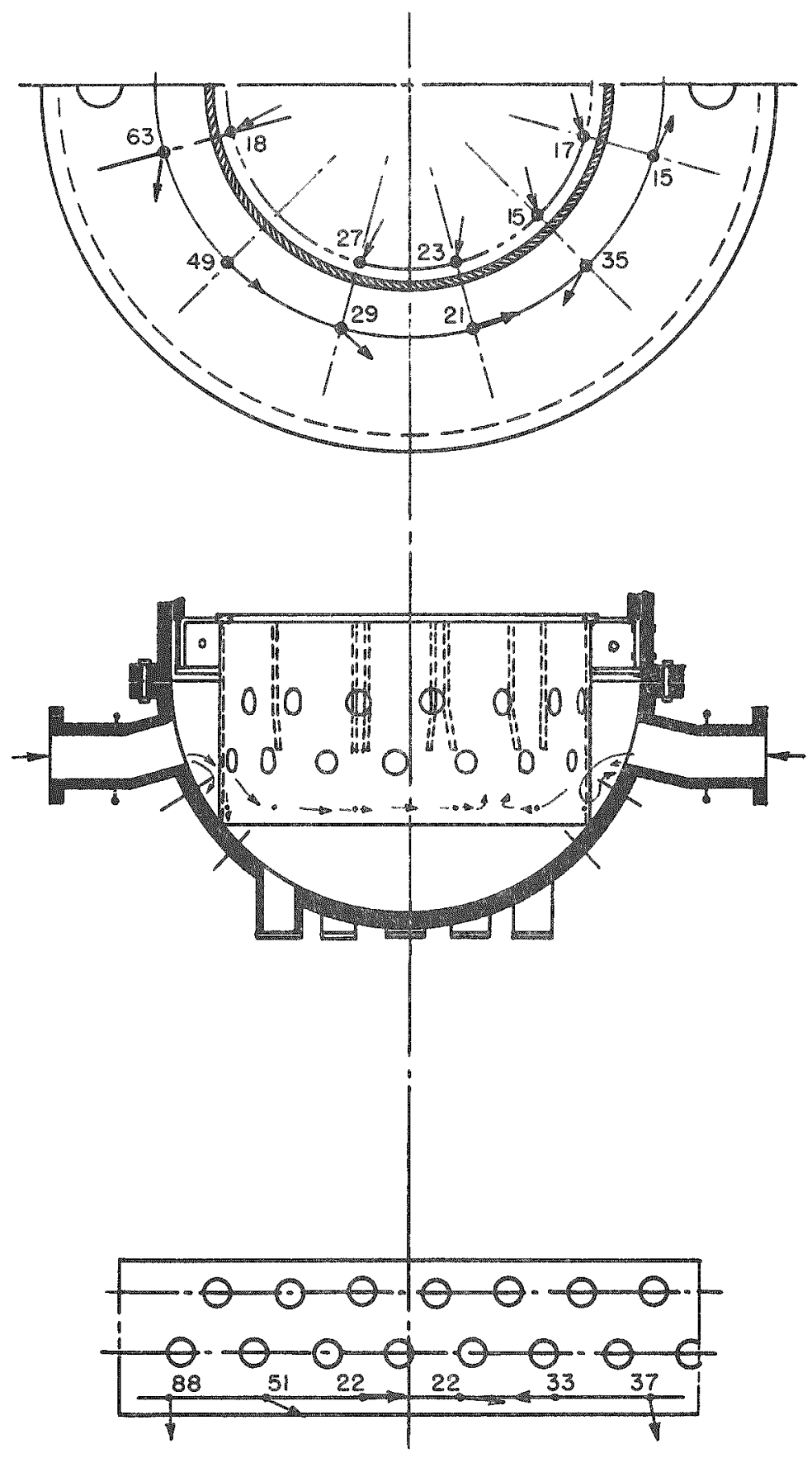

FIGURE 17. FLOW PATTERN IN LOWER PLENUM NEAR JUNCTION OF CORE-SUPPORT CYLINDER AND BOTTOM DOME FOR TWO-LOOP OPERATION

Arrows indicate flow direction and numbers indicate air velocity fps.

Helium velocities are 0.605 times air velocities. 


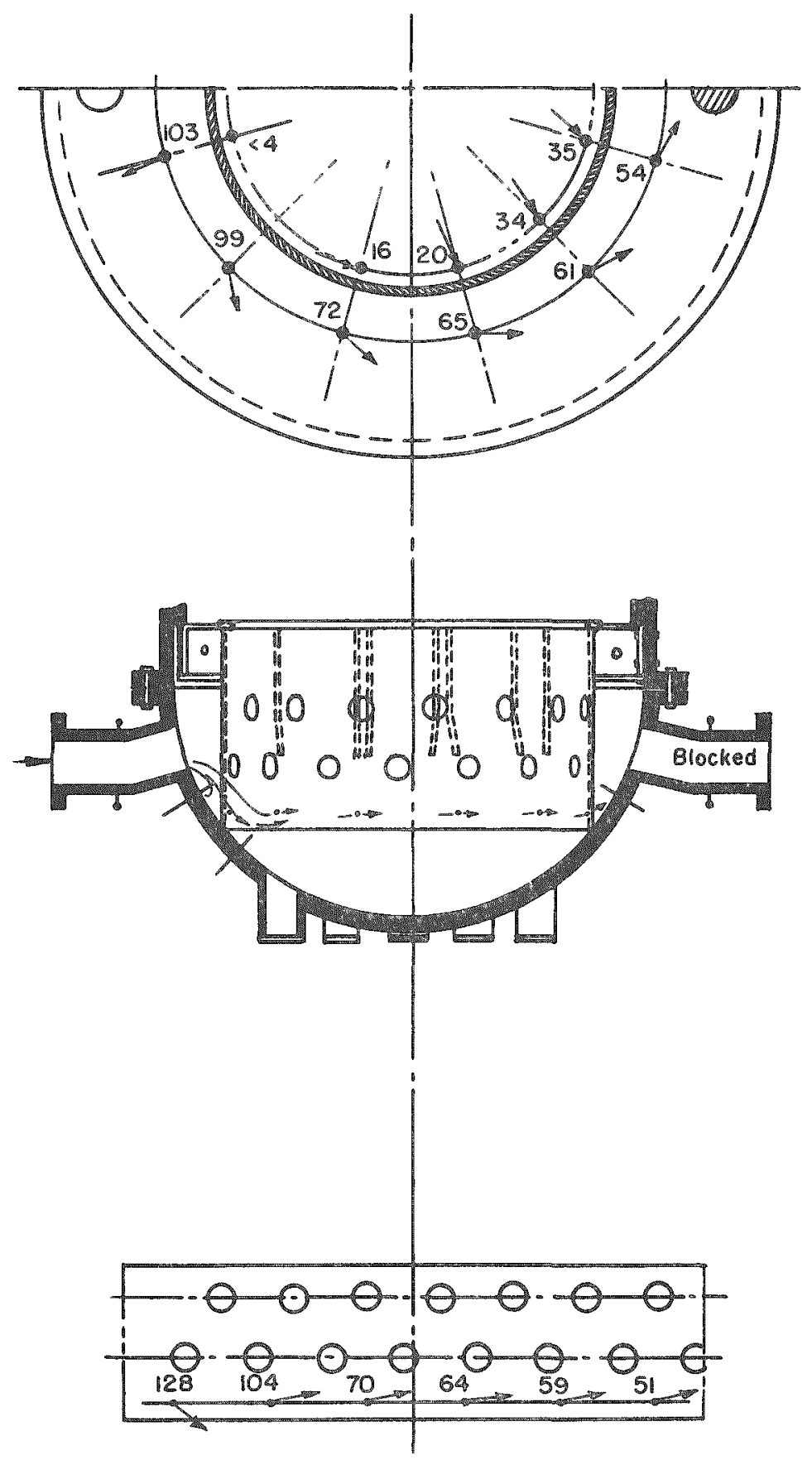

FIGURE 18. FLOW PATTERN IN LOWER PLENUM NEAR JUNCTION OF CORE-SUPPORT CYLINDER AND BCTTOM DOME FOR ONE-LOOP OPERATION

Arrows indicate flow dixection and numbers indicate aire velocity fps.

Helium velocilies a $1^{\circ} 0.383$ times air velocities. 
Figure 18 shows the flow directions and velocities measured with one loop operating. Velocities in the inlet plenum varied from 128 to $51 \mathrm{fps}$ and in the lower plenum the variation was from 35 fps to a value below the lower limit of the yaw probe, which is about $3-1 / 2 \mathrm{fps}$.

\section{Transition Studies}

In the prototype there is the possibility that under some conditions, with two loops operating, the flow rates through the two loops will not be equal. To investigate the effects of unequal flow through the two loops transition from two-loop to one-loop operation was studied in the model. The flow was varied from 100 per cent through one loop to 50 per cent through each loop in nine steps. At each step the water manometers showing all model pressures were checked for pressure fluctuations and for changes in core-flow distribution. With 80 to 90 per cent of model flow through one loop the fluctuations in core-orifice differentials increased to about \pm 0.7 per cent from a normal fluctuation of about \pm 0.4 per cent. Otherwise, the model operated normally under all test conditions.

\section{Pressure-Loss Studies}

In the air-flow model of the PEGCPR, air simulated the flow of helium in the pro tolype. In order to convert losses measured in the model to prototype conditions, the differences in density and velocity must be properly accounted for. This can be done readily by converting air-flow data to dimensionless terms suitable for use with heliumflow conditions. This is done in this report by expressing pressure losses as hedd losses or loss coefficients, which are obtained as the ratio of the loss to some appropriate velocity head, in consistent units. That is, the loss coefficient may be defined as:

$$
C=\frac{\Delta p}{q},
$$

where

$C$ is the loss coefficient

$\Delta P$ is the pressure differential

$q$ is the velocity pressure, $\rho \frac{V^{2}}{2 g}$

$g$ is the gravitational constant

$V$ is the velocity through the reference area

$\rho$ is the fluid density.

If the losses are expressed as loss coefficients based on local velocities in the flow region, they are independent of scale, velocity, and fluid properties, so long as the Reynolds number is well into the turbulent range and no change in the mode of flow occurs. 
In analyses of pressure-loss data from the PEGCPR flow model, loss coefficients based on local velocities were determined. The pressure of the air passing through the model changed from about 19 psia at the inlets to about 14.7 psia at the outlets with a resulting density change. Therefore, the loss coefficients were computed using local density. Predicted protolype pressure losses were then calculated using the local loss coefficient. These pressures are additive and can be used to predict over-all losses.

In general, all losses are expressed as differences in total pressures at points of measurement. Total pressures were computed from measured static pressures and computed velocity pressures.

'To compute pressure losses the model was divided into six regions. A discussion of each loss and its determination follows.

Region 1 extends from the inlet nozzle to the inlet plenum. The air entered the model through two 5.81-in.-diameter nozzles spaced 180 deg apart and flowed in both directions around the inlet plenum. At points about halfway between the inlets the streams from the two inlets met and formed stagnation points. The static pressures at the stagnation points were used as the total pressure in the inlet plenum.

Region 2 extends from the inlet plenum through the core-support cylinder to the lower plenum. The highest static pressure on the surface of the dome inside the coresupport cylinder was used as a total pressure.

Region 3 extends from the lower plenum to the upstream orifice pressure taps in the core tubes which simulate core fuel channels. The total pressure upstream of the orifices was calculated using the average static pressure and a computed velocity pressure.

Region 4 extends from upstream to downstream orifice pressure taps.

Region 5 extends from the downstream orifice pressure tap near the outlet end of the tube to the upper plenum. The total pressure in the upper plenum was assumed equal to the static pressure measured on the top dome directly above the core.

Region 6 extends from the upper plenum to the outlet nozzle. The total pressure in the outlet nozzle was computed using a measured static pressure and a computed velocity pressure.

Table 1 lists the experimental loss coefficients obtained from the air-flow model. Loss coefficients are reported for three flow rates when operating with two loops and for one flow rate with one loop operating. A compaxison of the data for two-loop operation shows that the losses are independent of Reynolds number within the limits of accuracy of the measurements. 
TABLE 1. LOCAL PRESSURE-LOSS COEFFICIENTS MEASURED IN MODEL

\begin{tabular}{|c|c|c|c|c|c|c|c|}
\hline \multirow[b]{2}{*}{ Region } & \multirow[b]{2}{*}{$\begin{array}{l}\text { Description } \\
\text { of Loss }\end{array}$} & \multicolumn{2}{|c|}{$\begin{array}{c}\text { Flow Area on Which } \\
\text { Local Loss Coefficient } \\
\text { Is Based }\end{array}$} & \multicolumn{4}{|c|}{$\begin{array}{c}\text { Experimental Local Model Loss Coefficients for } \\
\text { Indicated Inlet Nozzle Reynolds Number }\end{array}$} \\
\hline & & Location & $\begin{array}{c}\text { Area, } \\
\mathrm{ft}^{2}\end{array}$ & $7.10 \times 10^{5}$ & $\frac{\text { TwO Loop }}{6.46 \times 10^{5}}$ & $5.35 \times 10^{5}$ & $\frac{\text { One Loop }}{10.8 \times 10^{5}}$ \\
\hline 1 & Inlet loss & $\begin{array}{l}\text { Inlet nozzle, per } \\
\text { nozzle }\end{array}$ & 0.184 & 0.86 & 0.85 & 0.85 & 0.84 \\
\hline 3 & $\begin{array}{l}\text { Core-tube- } \\
\text { entrance loss }\end{array}$ & $\begin{array}{l}\text { Core-tube } \\
\text { flow area }\end{array}$ & 0.761 & 0.93 & 0.90 & 0.95 & 0.97 \\
\hline 4 & Orifice loss & $\begin{array}{l}\text { Core-tube } \\
\text { flow area }\end{array}$ & 0.761 & 12.24 & 12. 14 & 12.01 & 12.03 \\
\hline
\end{tabular}




\section{PROTOTYPE PRESSURE LOSSES}

The predicted pressure losses in the prototype were determined as the product of the local loss coefficients, from Table 1, and the appropriate prototype local velocity pressure. The calculations were based on the following prototype operating conditions:

\author{
Coolant \\ Two-loop flow rate, lb per hr \\ One-loop flow rate, $1 \mathrm{~b}$ per hro \\ Inlet pressure, psia \\ Inlet temperature, $\mathrm{F}$ \\ Outlet temperature, $\mathrm{F}$
}

\author{
Helium \\ $4.27 \times 10^{5}$ \\ $2.135 \times 10^{5}$ \\ 315 \\ 510 \\ 1050
}

Since axial-flow compressors will be used in the prototype installation, the oneloop flow rate will be between 50 and 55 per cent of the two-loop flow rate. Thus for calculation purposes one-loop flow rate was assumed to be one-half of the rated two-loop flow rate.

Table 2 summarizes the predicted prototype pressure losses excluding the fuelregion pressure loss. In the model the fuel-region pressure loss was simulated with orifices having approximately the correct pressure drop, considered as a loss coefficient based on velocity in the model inlets. However, the actual pressure loss for the fuel assemblies is to be measured in another program. From the table it can be seen that the inlet loss is a major porition of the total reactor loss excluding fuel-region losses.

TABLE 2. PREDICTED PROTOTYPE PRESSURES LOSSES BASED ON MODEL DATA

\begin{tabular}{|c|c|c|c|c|c|}
\hline \multirow[b]{3}{*}{ Region } & \multirow{3}{*}{$\begin{array}{c}\text { Description } \\
\text { of Loss }\end{array}$} & \multicolumn{2}{|c|}{$\begin{array}{l}\text { Flow Area Used in Obtaining } \\
\text { Local Velacity Pressure }\end{array}$} & \multirow{2}{*}{\multicolumn{2}{|c|}{$\begin{array}{c}\text { Predicted Prototype Pressure } \\
\text { Loss }(a), \text { psi }\end{array}$}} \\
\hline & & \multirow[b]{2}{*}{ Location } & \multirow{2}{*}{$\begin{array}{c}\text { Area, } \\
\mathrm{ft} 2\end{array}$} & & \\
\hline & & & & Two Loup & One Loop \\
\hline 1 & Inlet loss & Inlet nozzle & 2.948 & 0.30 & 0.29 \\
\hline 2 & $\begin{array}{l}\text { Core-support - } \\
\text { cylinder loss }\end{array}$ & $\begin{array}{l}\text { Core-support- } \\
\text { cylinder holes }\end{array}$ & 23.56 & 0.07 & 0.02 \\
\hline 3 & $\begin{array}{l}\text { Core-tube- } \\
\text { entrance loss }\end{array}$ & $\begin{array}{l}\text { Core-tube } \\
\text { flow area }\end{array}$ & 39.11 & 0.01 & 0.002 \\
\hline 5 & $\begin{array}{l}\text { Core-tube- } \\
\text { exit loss }\end{array}$ & $\begin{array}{l}\text { Core-tube } \\
\text { flow area }\end{array}$ & 34.88 & 0.01 & 0.003 \\
\hline \multirow[t]{2}{*}{6} & Outlet loss & Outlet nozzle & 3.142 & 0.06 & 0.07 \\
\hline & \multicolumn{3}{|c|}{ Total (excluding fuel-region loss) } & 0.45 & 0.385 \\
\hline
\end{tabular}

(a) Based on total helium flow of $4.27 \times 105 \mathrm{lb}$ per hr for two-loop operation and $2.135 \times 105 \mathrm{lb}$ per hr for one-loop operation. 


\section{ACKNOWLEDGMENTS}

The work described in this report was performed by L. J. Flanigan, G. R. Whitacre, and $K$. F. Kuehner under the supervision of $H$. R. Hazard. L. P. Carpenter and $F$. Hunton of Kaiser Engineers coordinated the work for Kaiser and contributed much to the over-all planning of the research. Their assistance is appreciated.

LJE:GRW:HRH/nb 